\title{
Numerical modeling of water-soluble solvents for enhancing oil recovery in heterogeneous chalk reservoirs
}

\author{
Mahdizadeh, M.; Eftekhari, Ali Akbar; Nick, H.M.
}

Published in:

Journal of Petroleum Science and Engineering

Link to article, DOI:

10.1016/j.petrol.2018.12.083

Publication date:

2019

Document Version

Peer reviewed version

Link back to DTU Orbit

Citation (APA):

Mahdizadeh, M., Eftekhari, A. A., \& Nick, H. M. (2019). Numerical modeling of water-soluble solvents for enhancing oil recovery in heterogeneous chalk reservoirs. Journal of Petroleum Science and Engineering, 175, 681-692. https://doi.org/10.1016/j.petrol.2018.12.083

\section{General rights}

Copyright and moral rights for the publications made accessible in the public portal are retained by the authors and/or other copyright owners and it is a condition of accessing publications that users recognise and abide by the legal requirements associated with these rights.

- Users may download and print one copy of any publication from the public portal for the purpose of private study or research.

- You may not further distribute the material or use it for any profit-making activity or commercial gain

- You may freely distribute the URL identifying the publication in the public portal 


\section{Accepted Manuscript}

Numerical modeling of water-soluble solvents for enhancing oil recovery in heterogeneous chalk reservoirs

M. Mahdizadeh, A.A. Eftekhar, H.M. Nick

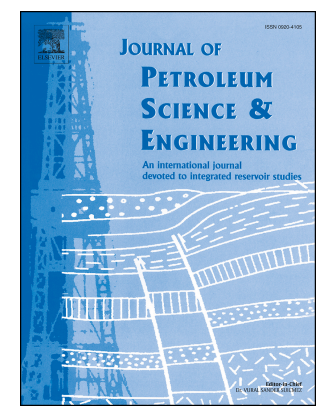

PII:

S0920-4105(18)31192-6

DOI:

https://doi.org/10.1016/j.petrol.2018.12.083

Reference: PETROL 5643

To appear in: Journal of Petroleum Science and Engineering

Received Date: 28 February 2018

Revised Date: 24 December 2018

Accepted Date: 29 December 2018

Please cite this article as: Mahdizadeh, M., Eftekhar, A.A., Nick, H.M., Numerical modeling of watersoluble solvents for enhancing oil recovery in heterogeneous chalk reservoirs, Journal of Petroleum Science and Engineering (2019), doi: https://doi.org/10.1016/j.petrol.2018.12.083.

This is a PDF file of an unedited manuscript that has been accepted for publication. As a service to our customers we are providing this early version of the manuscript. The manuscript will undergo copyediting, typesetting, and review of the resulting proof before it is published in its final form. Please note that during the production process errors may be discovered which could affect the content, and all legal disclaimers that apply to the journal pertain. 


\title{
Numerical Modeling of Water-Soluble Solvents for Enhancing Oil Recovery in Heterogeneous Chalk Reservoirs
}

M. Mahdizadeh*; A.A. Eftekhar*; H. M. Nick*

*Technical University of Denmark (DTU)

\begin{abstract}
Dimethyl Ether Waterflooding (DEW) is a promising water-soluble solvent-based EOR technique. Here, we study DEW mechanisms by developing a mathematical model taking into account the swelling and viscosity reduction of oil. Our analyses show that the swelling and viscosity reduction of oil cannot explain the observed increased recovery of DEW in the published core flooding data. Therefore, we define the residual oil saturation as a linear function of DME concentration in the oil phase to fit the model to the experimental data.

After model validation against a 1D core flooding experiment, we utilize the model to study the effect of permeability heterogeneity and the injected DME slug size on the recovery of oil from a water-flooded chalk reservoir. We observe a sharp increase in the ultimate recovery when the DME slug size increases from 0.2 to 1.8 pore volume with a DME concentration of $10 w t \%$. Since DME is an expensive agent, the optimal slug size requires an integrated economic evaluation. We calculate the increased Net Present Value (NPV) of DEW flooding in the heterogeneous chalk reservoirs compared to the conventional water flooding for two scenarios of well completions. By comparing the water breakthrough and DME induced recovery, we conclude that the most economical scenario for the DEW flooding is observed in the reservoirs with the lowest heterogeneity.
\end{abstract}



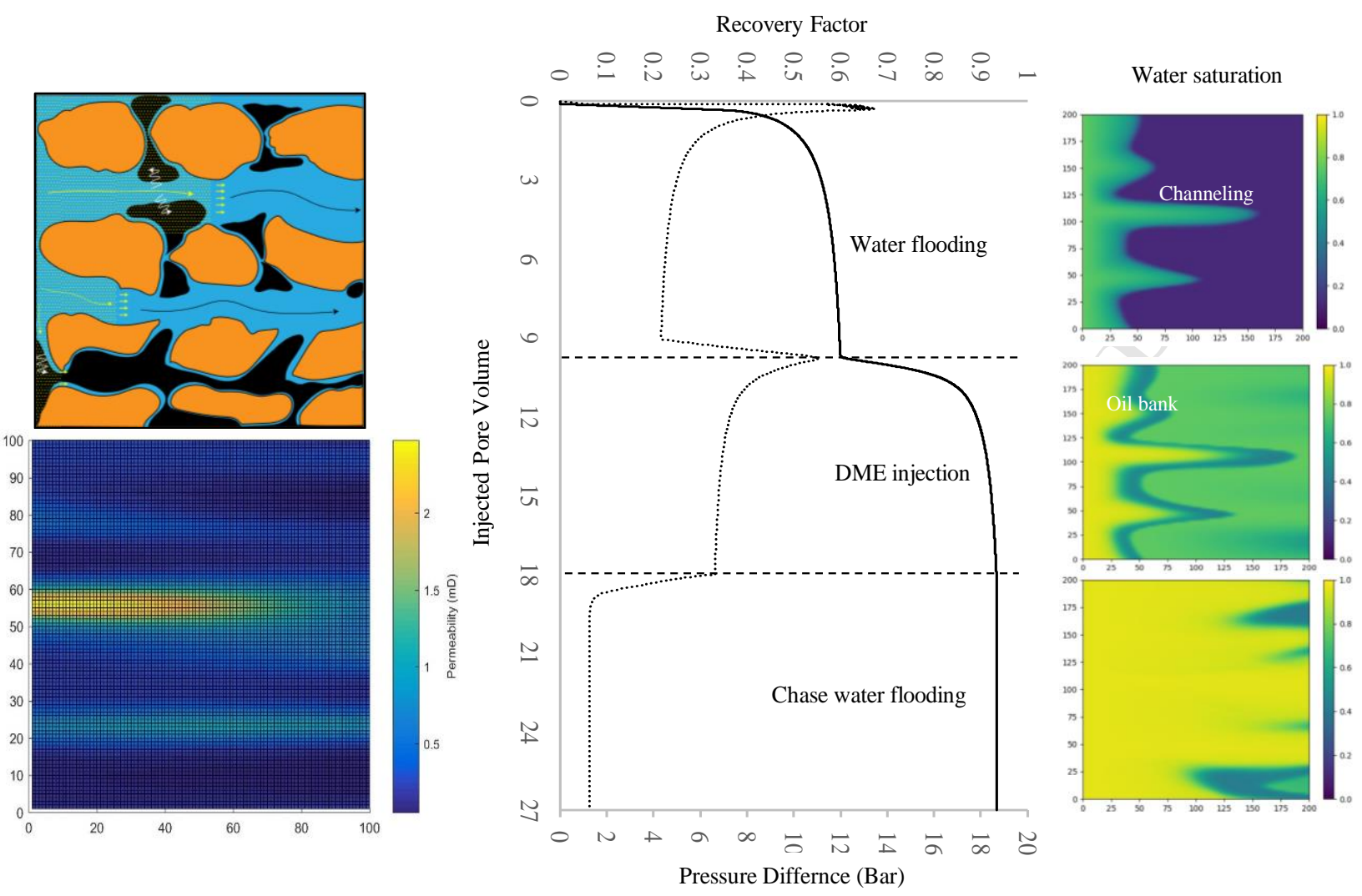


\section{Introduction}

Enhanced oil recovery (EOR) methods once oil price is high enough to make it economically feasible. The fast depletion and the declining discoveries of the conventional oil reserves are creating the circumstances for extensive deployment of Enhanced Oil Recovery (EOR) (Muggeridge et al., 2014), which can increase the recovery of the remaining oil after the primary production and the conventional water flooding. One of the mature techniques for EOR is solvent injection (Lake et al., 2014), in which the solvent is injected into the reservoir. The solvent can be a pure hydrocarbon or a component that is mutually soluble in both oil and water. In the latter, the solvent can be dissolved as an aqueous mixture. Based on the nature of the solvent, this method can reduce the viscosity and the density of the oil phase or reduce the interfacial tension between the water and oil phases. It can also change the wettability of the rock when the solvent interacts with and alters the rock surface. One of the agents that recently became attractive for the solvent injection EOR is Dimethyl ether (DME), also known as methoxymethane.

DME, is a non-toxic organic compound which is used as the feedstock for the production of the methylating agent, transport fuels/additive, and domestic application (Groot et al., 2016a). DME is a colorless gas at standard condition but it liquefies at low temperature or high pressure (Fujimoto et al., 2007). It can be manufactured from methane, which is supplied by natural gas or gasification of coal (Groot et al., 2016b). DME is miscible with oil and due to its slight polarity, it also can be dissolved in water, which makes it an attractive candidate for tertiary recovery as an additive to the injected water.

DME enhanced water-flooding (DEW) is a novel EOR technique, first introduced by Shell (M. Chahardowli et al., 2016; Chernetsky et al., 2015; Parsons et al., 2017), that can significantly increase the oil recovery (Chahardowli et al., 2013; Mohammad Chahardowli et al., 2016; Javanmard et al., 2018; Riele et al., 2016). Initially, water flooding is performed to produce oil from a virgin reservoir (Figure 1, Step 2). Then DME is dissolved in water and injected into the reservoir. DME molecules have a higher affinity towards the hydrocarbons; therefore, when DME gets in contact with the reservoir fluid, it partitions into the hydrocarbon phase. This results in the oil swelling and viscosity reduction (Figure 1, Step 3) (Chernetsky et al., 2015). Once the remaining oil is expanded, oil phase connectivity increases, and the residual oil is mobilized (Figure 1, Step 4). Therefore, the oil in small pores that were immobile during the water-flooding can be produced. This also creates new pathway in the reservoir, which were unreachable during the initial water-flooding (Figure 1, Step 5). It is also suggested that the interaction of DME with the reservoir fluid and rock can alter the wettability (Chahardowli et al., 2013). This leads to a large reduction of the residual oil saturation.

DEW flooding can be applied to both Carbonate (M. Chahardowli et al., 2016; Javanmard et al., 2018) and Clastic reservoirs (M. Chahardowli et al., 2016) regardless of rock permeability (Groot et al., 2016a). It can also be implemented as tertiary or part of secondary recovery processes (Chernetsky et al., 2015). The time span of DEW injection in fractured or heterogeneous reservoirs is significantly less than reservoirs with less complexity, due to early breakthrough. Since DME is an expensive agent, it is very important to reproduce it from the reservoir by chase water flooding (CWF). In CWF, chase water is injected after DME slug to dissolve the remaining DME in the reservoir (Figure 1, Step 6). The recovered DME can be used for reinjection or injection in neighboring wells. The efficiency of DME recovery depends on the heterogeneity and well completion (Groot et al., 2016b). Through a series of core flooding tests, Chernetsky et al. (2015) showed that most of the injected DME could be recovered from the core by only one pore volume injection of chase water. 
The focus in the majority of recent publications is on the measurements and modeling of DME-water-oil phase behavior (M. Chahardowli et al., 2016; Ram R. Ratnakar et al., 2016; R. R. Ratnakar et al., 2016; Ratnakar et al., 2017a, 2017b) or DEW core scale modeling (M. Chahardowli et al., 2016; Groot et al., 2016a). Moreover, in all of the previous publications, the swelling and viscosity reduction of oil are suggested as the main mechanisms of DEW enhanced oil recovery, which seems inadequate given the small difference between the liquid density of DME and oil (Groot et al., 2016c), and large extent of extra oil recovery by DEW, which seems to be more than the limited equilibrium swelling. This is one of the aspects that will be discussed in this paper. The other aspect is the feasibility of the DEW flooding in the North Sea chalk reservoirs.

DEW flooding may not be always an economically attractive EOR method due to the high cost of DME. Therefore, it is important to take into account economic analysis. In this paper, we seek to find conditions under which DEW flooding becomes efficient and economically feasible. The purpose of this study is to analyze the driving mechanisms and sensitivities of DEW process to various process parameters as well as the effectiveness of DME flooding in different heterogeneous fields. To that end, we develop a new mathematical model, history match it to the published experimental data, and conduct simulations on utilizing several heterogeneous permeability fields. Moreover, economic analysis is included for different scenarios to analyze the feasibility of DEW flooding in the Danish sector of the North Sea. 


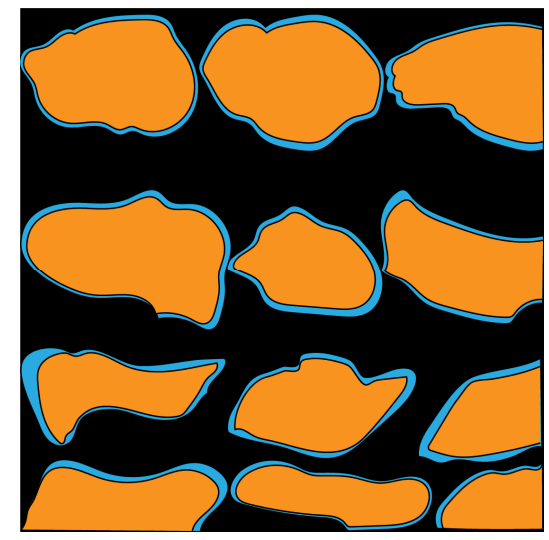

1. Initial reservoir saturated with oil (black), water films (blue) and the grains (brown).

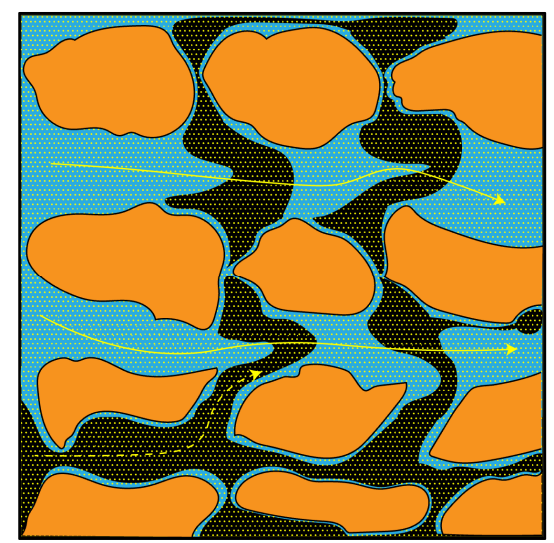

4. Residual oil connectivity. Dashed line shows new pathway.

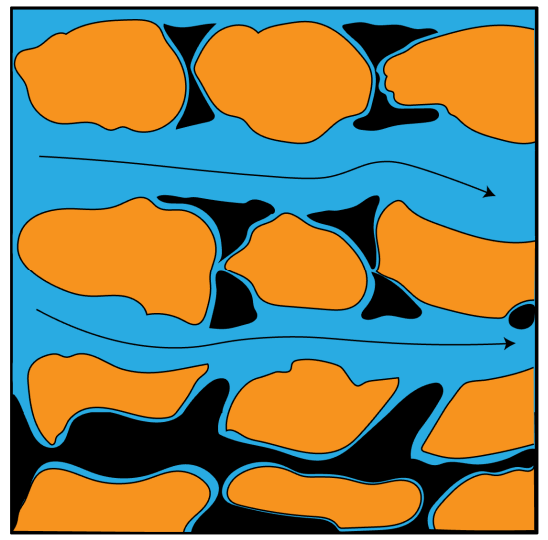

2. Conventional water flooding. Black arrows show water flow paths and black areas shows remaining oil.

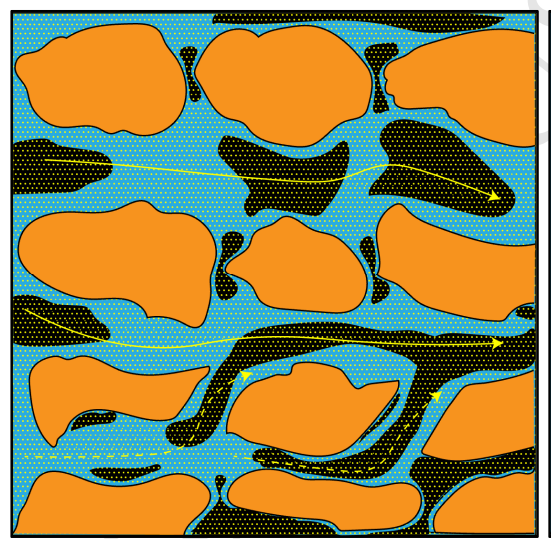

5. Residual oil mobilization.

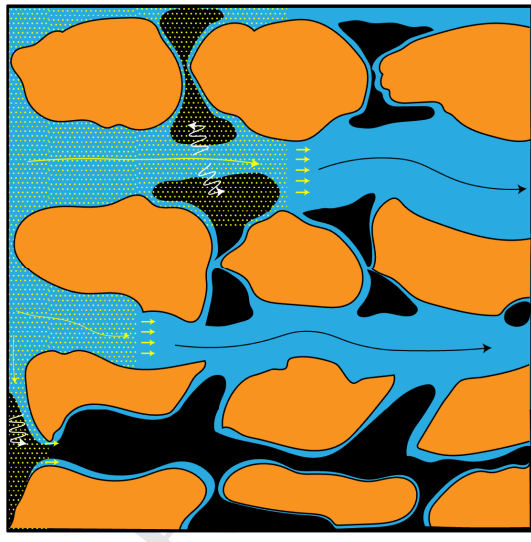

3. DME injection. White arrows show DME diffusion, yellow arrows show DME flow path, small yellow arrows show DME front and yellow dots are DME molecules.

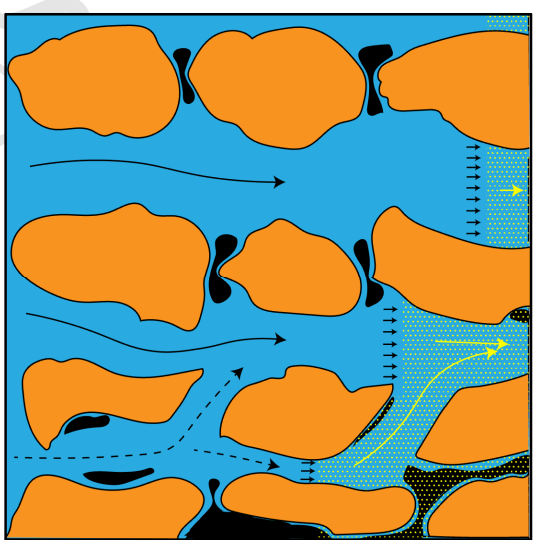

6. Chase water flooding. Small black arrows show water front. 


\section{Methodology}

\subsection{Governing Equations}

For the flow of DEW in porous media, the system consists of two phases (oil and water) and three components (oil, brine and DME). The mass conservation of Oil-Brine-Solvent can be written in the following form:

$$
\begin{gathered}
\frac{\partial}{\partial t}\left(\varphi \rho_{w} S_{w}\right)+\nabla \cdot\left(\mathbf{u}_{w} \rho_{w}\right)=0, \\
\frac{\partial}{\partial t}\left(\varphi \rho_{o} S_{o}\right)+\nabla \cdot\left(\mathbf{u}_{o} \rho_{o}\right)=0, \\
\frac{\partial}{\partial t}\left\{\varphi\left(c_{w} S_{w} \rho_{w}+c_{o}\left(1-S_{w}\right) \rho_{o}\right)\right\}+\nabla \cdot\left(\mathbf{u}_{o} c_{o} \rho_{o}+\mathbf{u}_{w} c_{w} \rho_{w}\right)=0,
\end{gathered}
$$

where the subscripts $w$ and $o$ denote water and oil phase. $S[-], \rho\left[\mathrm{kg} / \mathrm{m}^{3}\right]$ and $\mathbf{u}[\mathrm{m} / \mathrm{s}]$ denote the saturation, density and Darcy velocity of the phase $i$ ( $w$ or $o$ ), $\varphi[-]$ is reservoir porosity and $c[-]$ is the mass fraction of DME in the phase $i$ ( $w$ or $o$ ) at thermodynamic equilibrium, i.e.,

$$
K=\frac{c_{o}}{c_{w}}
$$

where $K$ [-] denotes the partition coefficient. The viscosity and density of the oil phase are a function of DME concentration, which we provide as polynomial fits to the experimental data.

The above equations are supplemented with the extended Darcy's law, neglecting the gravity effect:

$$
\mathbf{u}_{w}=-\frac{k k_{r w}}{\mu_{w}} \nabla p_{w},
$$

$$
\mathbf{u}_{o}=-\frac{k k_{r o}}{\mu_{o}} \nabla p_{o}
$$

Where $k\left[\mathrm{~m}^{2}\right]$ denotes permeability, $k_{r}[-]$ is relative permeability of the phases, $\mu[\mathrm{Pa} . \mathrm{s}]$ and $p[\mathrm{~Pa}]$ denote the viscosity and pressure of the phase $i(w$ or $o$ ). The water and oil pressure are related by the capillary pressure, which is determined by the following relation:

$$
p_{c}=p_{o}-p_{w}=p_{c e}\left(\frac{S_{w}-S_{w c}}{1-S_{w c}}\right)^{-1 / \lambda}
$$

where $p_{c}[\mathrm{~Pa}]$ denotes the capillary pressure, $p_{c e}[\mathrm{~Pa}]$ denotes the capillary entry pressure, $\lambda^{\prime}[-]$ is the sorting factor with an average value of 2.4 for chalk (Christoffersen and Whitson, 1995; Tweheyo et al., 2001 ), and $S_{w c}[-]$ is the connate water saturation.

The relative permeability is defined as a function of water saturation by the Brooks-Corey equation: 
87

$$
\begin{aligned}
& k_{r w}=k_{r w, 0}\left(\frac{S_{w}-S_{w c}}{1-S_{w c}-S_{o r}}\right)^{n_{w}}, \\
& k_{r o}=k_{r o, 0}\left(\frac{1-S_{w}-S_{o r}}{1-S_{w c}-S_{o r}}\right)^{n_{o}} .
\end{aligned}
$$

The residual oil saturation, $S_{o r}[-]$, is defined as a linear function of DME concentration in the oleic phase, i.e.,

$$
S_{o r}=-\frac{S_{o r, W F}-S_{o r, D E W}}{c_{o, D E W}} c_{o}+S_{o r, W F}
$$

where $S_{o r, W F}[-]$ is the residual oil saturation that is measured for the conventional water flooding without DME, $c_{o, D E W}$ [mass fraction] is the equilibrium concentration of DME in the oil phase for the DEW flooding, and $S_{\text {Or, DEW }}$ is the residual oil saturation to DEW flooding. Eq. (8), which is the novel part of this model, needs the measurement of the residual oil saturation in the conventional water flooding and a DEW flooding with a DME-saturated aqueous phase.

\section{2. $\quad$ PVT Modeling}

Detailed PVT models for the DME-water-oil system are studied elsewhere, e.g., (Ratnakar et al., 2017b). Here, we fit polynomial equations to the reported experimental data for the partition coefficient, density, and viscosity of oil, which are reported by (Chernetsky et al., 2015). For the partition coefficient and the oil density, we fit a linear function and for the oil viscosity, we fit a polynomial function to the experimental data and use them in the mass balance equations. Other thermodynamic and transport properties are reported in Table 1 .
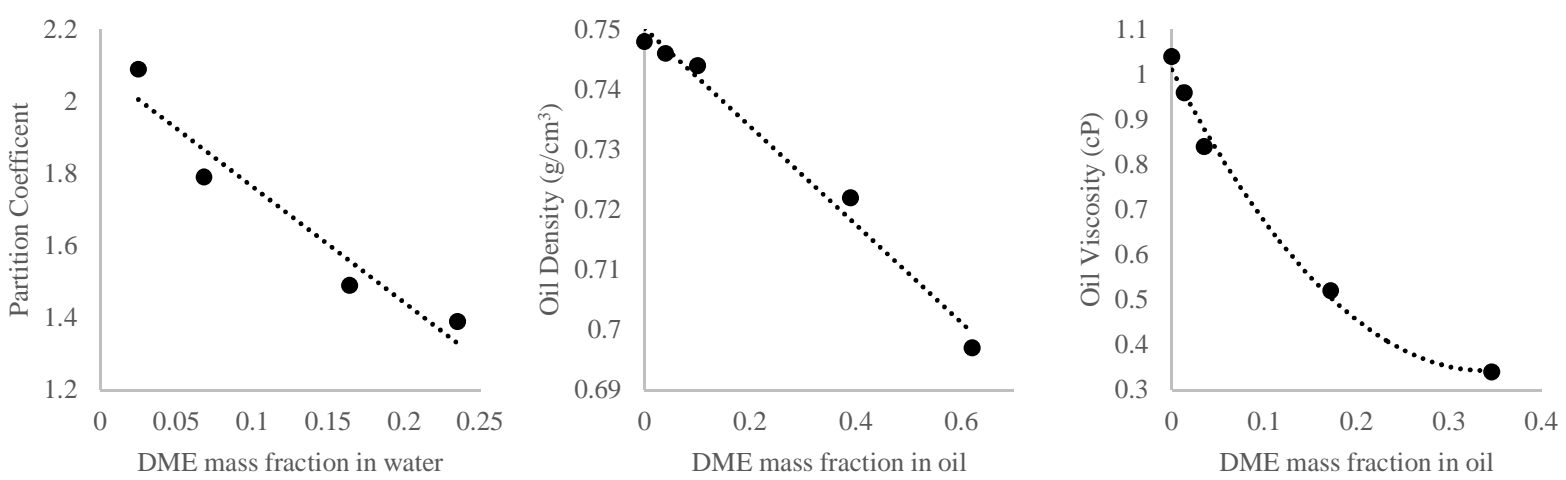

Figure 2. Partition coefficient of DME for $1.4 \%$ brine, Density and Viscosity of oil/DME mixture at $70^{\circ} \mathrm{C}$ and 2000 psia

Table 1- Thermodynamic and transport properties of oil and water

\begin{tabular}{lccc}
\hline Parameter & Density (Pa.s) & Viscosity $\left(\mathrm{kg} / \mathrm{m}^{3}\right)$ & Note \\
\hline Oil & 748 & 0.00104 & $70^{\circ} \mathrm{C}, 2000 \mathrm{psi}$ \\
Water & 983.6 & 0.000407 & $70^{\circ} \mathrm{C}, 2000 \mathrm{psi}$ \\
\hline
\end{tabular}


107

108

109

110

111

112

113 where $t, R_{t}$ and $N$ denote the injection period, cash flow
utilized for the NPV calculations are listed in Table 2.

\subsection{Net Present Value} based on the cash flow over the period of the field development:

In order to investigate economic aspects of DEW operation, we calculate the Net Present Value (NPV)

$$
N P V(i, N)=\sum_{t=0}^{N} \frac{R_{t}}{(1+i)^{t}}
$$

Table 2. Parameters used in NPV calculations

\begin{tabular}{lcc}
\hline Parameters & Value & Unit \\
\hline Infl. CAPEX \& OPEX & 4.00 & $\%$ \\
Infl. Oil \& gas Price & 4.00 & $\%$ \\
Discount & 10.00 & $\%$ \\
Royalty & 8.50 & $\%$ \\
Oil Pipeline Charge & 5.00 & $\%$ \\
Oil Price & 50 & $\$ / b b l$ \\
CAPEX in the first year for horizontal well scheme & 30 & Million Danish Krone \\
CAPEX in the first year for vertical well scheme & 15 & Million Danish Krone \\
CAPEX for DME injection & 30 & Million Danish Krone \\
OPEX & 10 & Million Danish Krone \\
The efficiency of the DME recycling & 80 & $\%$ \\
\hline
\end{tabular}




\section{Model Description:}

\subsection{One-dimensional Core Scale Model}

We discretize the system of equations using the cell centered finite volume method and developed a onedimensional numerical simulator in the Julia programming language with an inhouse finite volume solver (Eftekhari, 2017; Eftekhari and Schüller, 2015). For simplicity, the gravitational force is ignored. We study the effect of capillary pressure, as shown in Figure 4. However, it has a negligible effect on the prediction of the recovery factor and is disregarded in other simulations. Figure 3, shows a onedimensional two-phase system where the producer places at $x=\mathrm{L}$ and the injector places at $x=0$, with a uniform initial water saturation at the beginning of the operation $(t=0)$.

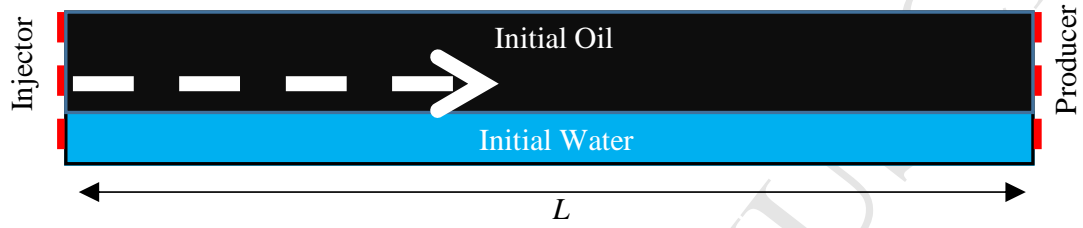

Figure 3. Schematic view of the one-dimensional DEW model at the beginning of the operation.

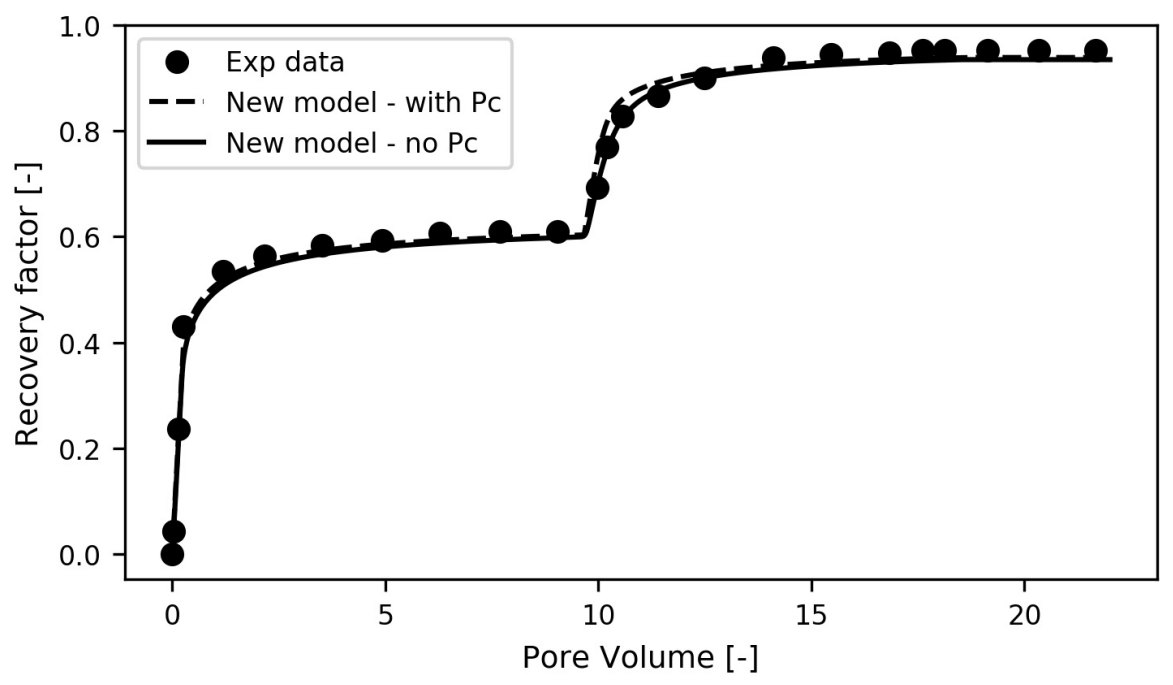

Figure 4-Effect of capillary pressure on the simulation results; the dashed line shows the model with capillary forces included

The DEW experiments were conducted for a carbonate reservoir core and a light Middle East crude (Chernetsky et al., 2015). The two reported DEW experiments are:

1. Continuous DEW injection: 9 pore volumes (PV) initial water flooding followed by $9 \mathrm{PV}$ slug size of DME and 4 PV chase water flooding.

2. Short DEW slug: 13.4 PV initial water flooding followed by 0.3 PV slug size of DME and 3.3 PV chase water flooding.

The main parameters of the experiments are summarized in Table 3: 
Table 3. The core flooding parameters (Chernetsky et al., 2015)

\begin{tabular}{lccc}
\hline Properties & Expriment1 & Expriment2 & Unit \\
\hline Core length & 5 & 5 & $\mathrm{~cm}$ \\
Core diameter & 2.5 & 2.5 & $\mathrm{~cm}$ \\
Porosity & 0.256 & 0.256 & \\
Permeability & 1 & 0.8 & $\mathrm{mD}$ \\
Injection rate & 0.0012 & 0.0017 & $\mathrm{~cm}^{3} / \mathrm{day}$ \\
Initial water saturation & 0.333 & 0.262 & \\
DME concentration & 10 & 10 & ${ }^{\mathrm{wt}} \%$ \\
Reservoir temperature & 70 & 70 & ${ }^{\circ} \mathrm{C}$ \\
Reservoir pressure & 2000 & 2000 & $\mathrm{psia}$ \\
\hline
\end{tabular}

We modelled the experiments of (Chernetsky et al., 2015) by discretizing Equations (1) to (3) using an inhouse finite volume solver (Eftekhari, 2017) written in Julia programming language (Bezanson et al., 2014). The numerical method is validated with the benchmark analytical solutions (Lake et al., 2014; Pope, 1980). The water and oil relative permeability parameters, i.e., $S_{o r}, S_{w c}, k_{r w}, k_{r o}, n_{o}$ and $n_{w}$ are determined by fitting the model to the measured oil recovery factor and pressure drop of the secondary water flooding experiments. The optimization is done using the NLopt package (Johnson, 2015). All the codes are available as open source software packages.

\subsection{Two-dimensional Homogeneous Chalk Reservoir Model}

In this section, the proposed 1D core-flood model is expanded to a $2 \mathrm{D}$ homogeneous field scale to investigate the effect of dimension and scaling on the transport process and study the performance of different well completions in chalk reservoirs.

The numerical experiment consists of three stages: Initially, three pore volumes of water flooding displaces oil to the remaining oil saturation. In the next step, one pore volume of DEW slug is injected to form and produce the oil bank, and finally, three pore volumes of chase water is injected to back-produce the DME. Since the reservoir is homogeneous, the oil recovery and pressure drop are identical to the 1D core scale model. The purpose of this section is to study the efficiency of DEW flooding in chalk reservoir for two scenarios of well completions. Additionally, the net present value of different well completions are studied for water flooding and DME enhanced water flooding.

In the first scenario, two horizontal wells (one for injection and one for production) are perforated parallel to each other with $200 \mathrm{~m}$ well spacing (Figure 5, left). The injection rate is constant and equal to 410 $\mathrm{m}^{3} /$ day and the bottom-hole pressure is identical to the reservoir pressure. The size of the reservoir is assumed to be $200 \mathrm{~m} \times 200 \mathrm{~m}$ with a thickness of $20 \mathrm{~m}$. The rest of the fluid properties are extracted from the previous model of 1D core-flooding. The reservoir is considered carbonate chalk and the petrophysical properties are obtained from (Tweheyo et al., 2001).

In the second scenario, two vertical wells are drilled in the two corners of the reservoir (Figure 5, right). The fluid and rock properties, the size of the reservoir and the injection rate are identical to the first scenario. The simulation of both cases is performed with equal grid size and time step. 

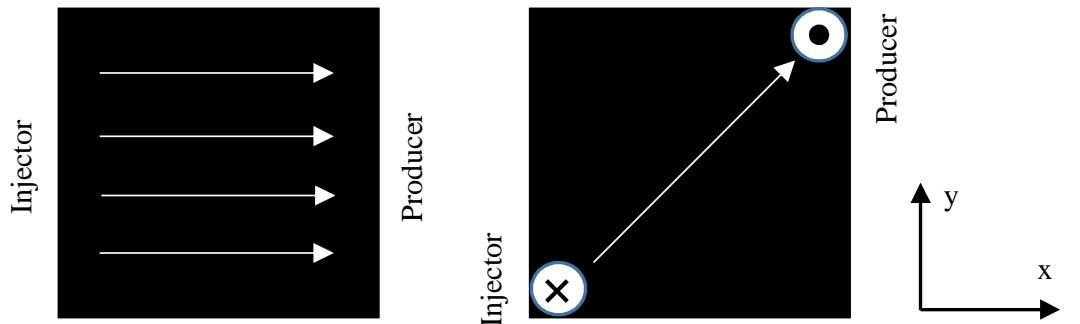

\section{Figure 5. Schematic view of horizontal scheme (left) and vertical scheme (right) of well completion. The white arrows show the direction of the flow.}

\subsection{Two-dimensional Heterogeneous Chalk Reservoir Scale Model}

In this section, the efficiency of DME flooding in different heterogeneous fields is studied by conducting simulations utilizing several heterogeneous permeability fields. A random field generator, FGEN, developed by (Robin et al., 1993), is utilized to generate heterogeneous 2D permeability fields. Several studies suggest that the probability density function of hydraulic conductivity is log-normal, e.g., (Dagan, 2012). If the permeability $(k)$ is log-normally distributed, a new parameter, $Y=\ln (k)$ can be defined which is normally distributed. By applying an isotropic Gaussian correlation function for the logpermeability, the following expression is obtained:

$$
R(h)=\exp \left(-\frac{h}{\lambda}\right)^{2}
$$

Where $\lambda$ and $h$ denote correlation length and Euclidean distance, respectively. Therefore, a normal distribution, $Y$, with sample size given by the number of elements in the mesh can be formed with a given mean permeability $(\mu)$ and variance $\left(\sigma_{f}^{2}\right)$ (Nick et al., 2009).

The capillary force as well as the gravity effect are neglected from the model. For simplicity, the porosity is kept constant $(\varphi=0.256)$ and the rest of the fluid properties are extracted from the 2D homogenous chalk reservoir. The reservoir is discretized by $100 \times 100$ elements. Thereby, the dimension of each block is equal to $2 m \times 2 m \times 20 m$.

Figure 6, illustrates six heterogeneous permeability fields that were generated by the random field generator, FGEN. Filed 1 has equal correlation length in $x$ and $y$ direction while Field2, Field 3 and Field4 have larger correlation length in $x$ direction compared to $y$ direction. Field5 has the largest correlation length in $x$ direction and Field 6 has the largest variance compared to the rest. The utilized parameters for generation of each field are shown in Figure 6. 


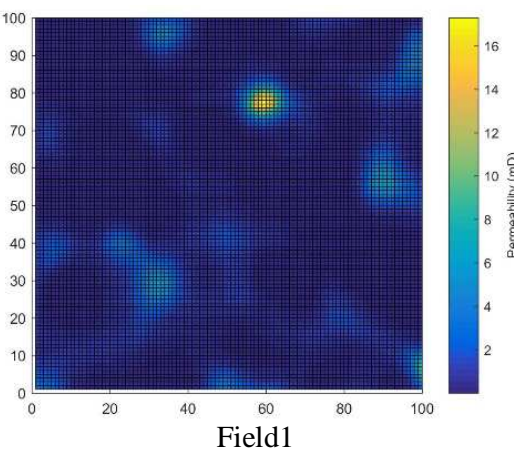

$\left(\sigma_{f}^{2}=1.9, \lambda_{x}=\lambda_{y}=20, \mu=0.71\right)$

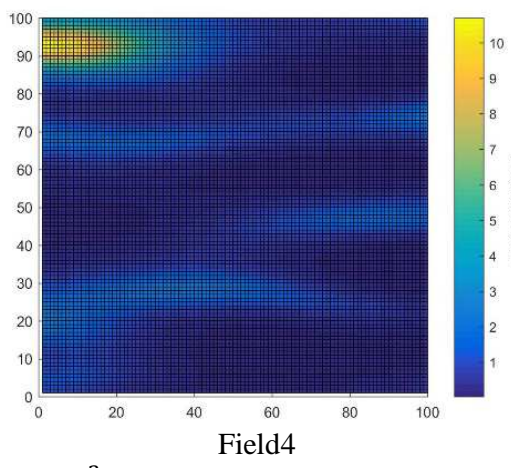

$\left(\sigma_{f}^{2}=1.2, \lambda_{x}=5 \lambda_{y}=100, \mu=0.87\right)$

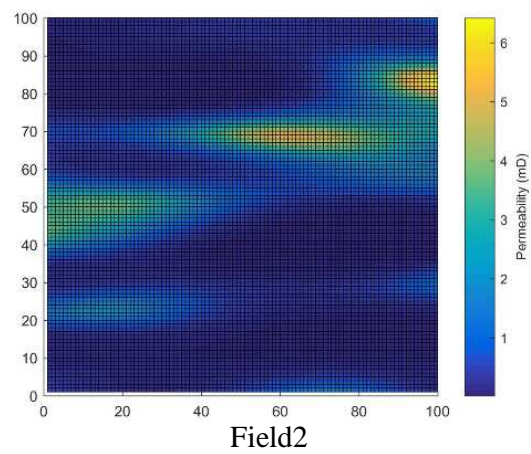

$\left(\sigma_{f}^{2}=1.8, \lambda_{x}=5 \lambda_{y}=100, \mu=0.77\right)$

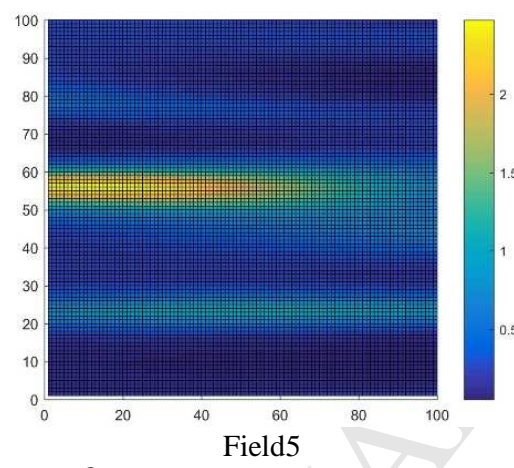

$\left(\sigma_{f}^{2}=0.7, \lambda_{x}=20 \lambda_{y}=400, \mu=0.42\right)$

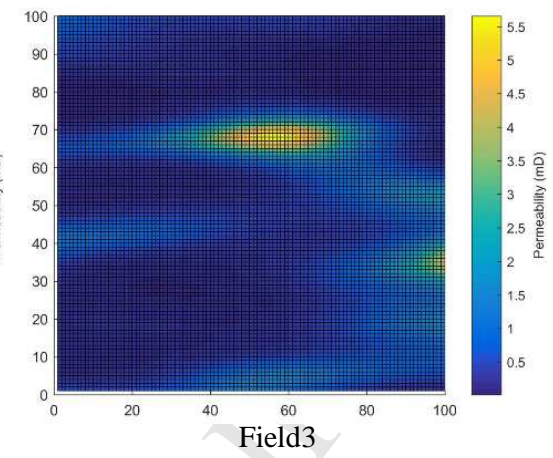

$\left(\sigma_{f}^{2}=1.2, \lambda_{x}=5 \lambda_{y}=100, \mu=0.59\right)$

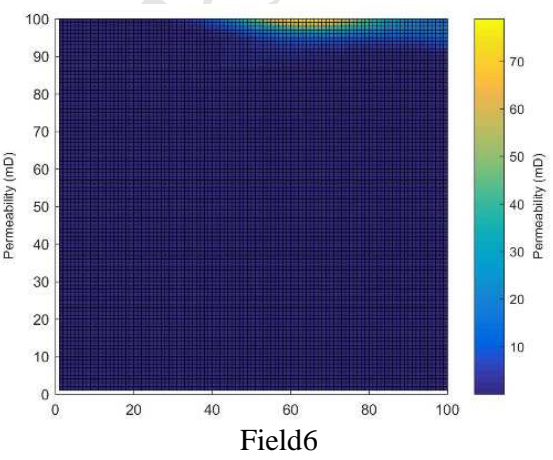

$\left(\sigma_{f}^{2}=5.4, \lambda_{x}=5 \lambda_{y}=100, \mu=1.40\right)$

Figure 6. Heterogeneous permeability field discretized with $100 \times 100$ elements. The values of variance $\left(\sigma_{f}^{2}[-]\right)$, correlation length in $x$ and $y$ direction $(\lambda x[m] ; \lambda y[m])$ and the mean permeability $(\mu[\mathrm{mD}])$ are listed for each field.

Several simulations are conducted to observe the performance of DEW flooding in heterogeneous reservoirs. Initially, three pore volumes of water is injected followed by one pore volume DME solution with a DME concentration of $10 w t \%$. Finally, three pore volumes of chase water is injected to back produce the injected solvent. In order to investigate the effect of solvent slug, several simulations are conducted with different DME slug sizes and their NPV are analyzed. 


\section{Results and Discussion}

\subsection{One-dimensional Core Scale Model}

By history matching the oil recovery and pressure drop during initial water flooding, the relative permeability parameters for two DME experiments (Continuous and Slug DME injection) are determined and presented in Table 4 . Note that the parameters are obtained by history matching only the water flooding experiments. For the DEW flooding, only the residual oil saturation is adjusted based on the concentration of DME in the oil phase, as shown in Eq. (8). We also study the effect of capillary pressure, which showed no significant effect on the predictions of the model.

Table 4. The values of relative permeability parameters from history matching

\begin{tabular}{lcc}
\hline Properties & Expriment1 & Expriment2 \\
\hline$S_{o r, W F}$ & 0.25 & 0.32 \\
$S_{o r, D E W}$ & 0.03 & 0.03 \\
$S_{w c}$ & 0.39 & 0.32 \\
$k_{r w, O}$ & 0.27 & 0.56 \\
$k_{r o, O}$ & 0.12 & 0.37 \\
$n_{o}$ & 1.92 & 2.39 \\
$n_{w}$ & 1.88 & 2.41 \\
\hline
\end{tabular}

Our simulation results, depicted in Figure 7, show that the oil swelling and the oil viscosity reduction in DME enhanced waterflooding cannot explain the observed oil recovery, and more research is required to identify other mechanisms. One possible explanation for the very low residual oil saturation is the change of wettability, similar to the carbonated water flooding (Foroozesh et al., 2016; Kechut et al., 2011; Riazi et al., 2009). This can occur due to the removal of the polar groups (Buckley et al., 1989, 1998; Buckley, 1994) from the surface of the rock by the DME-water solution, which alters the wettability of the carbonate rock from oil-wet to mixed- and water-wet. To reflect this in our model, we define the residual oil saturation as a linear function of the DME concentration in the oil phase. The new model can match the oil recovery and the pressure drop experimental data.

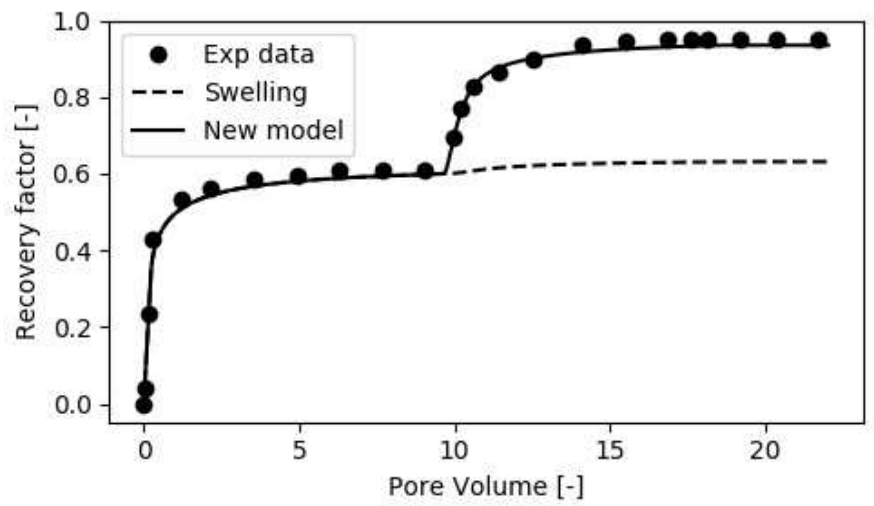

Figure 7. Comparing the simulation results of the swelling/viscosity reduction mechanism (dashed line) with the swelling/viscosity reduction/residual oil reduction mechanism (solid line)

Figure 8 illustrates the oil recovery (solid line) and pressure drop (dashed line) over the core for a continuous DEW injection. Circular and triangular markers show the lab data. It can be observed that 
there is a good agreement between the simulated and measured oil recovery. At the beginning of DEW flooding, pressure drop increases which implies the oil swelling and the formation of the oil bank. When DME is injected into the core, it takes one pore volume until the first signs of the extra oil recovery is observed at the outlet of the core. At the later stages of DEW injection, the pressure differential over the core does not decline in line with the oil bank production as predicted by the numerical model; but the pressure drop remains rather constant. A possible explanation for such a behavior might be the redistribution of particles in the core. Moreover, the presence of DME reduces the water-oil interfacial tension, which can cause the formation of a stable water-oil emulsion. We could not observe this behavior (i.e., a constant large pressure drop) in our own DEW flooding experiments (for this range of DME concentration in the injected water), conducted on the chalk cores from the Danish sector of the North Sea (Javanmard et al., 2018).

Figure 9 shows the core flooding data and the numerical calculations for the second DEW injection experiment. In this case, the ultimate recovery increases $10 \%$ for only 0.3 pore volume slug of DME injection after the initial water flooding. Although the experimental data for slug injection is noisy, a good agreement between the model and experiment is achieved.

For both DEW experiments, a good match is observed with simulation. This implies that our model, which shifts the oil relative permeability curve by defining the residual oil saturation as a function of DME concentration, is adequate for the simulation of DEW flooding.

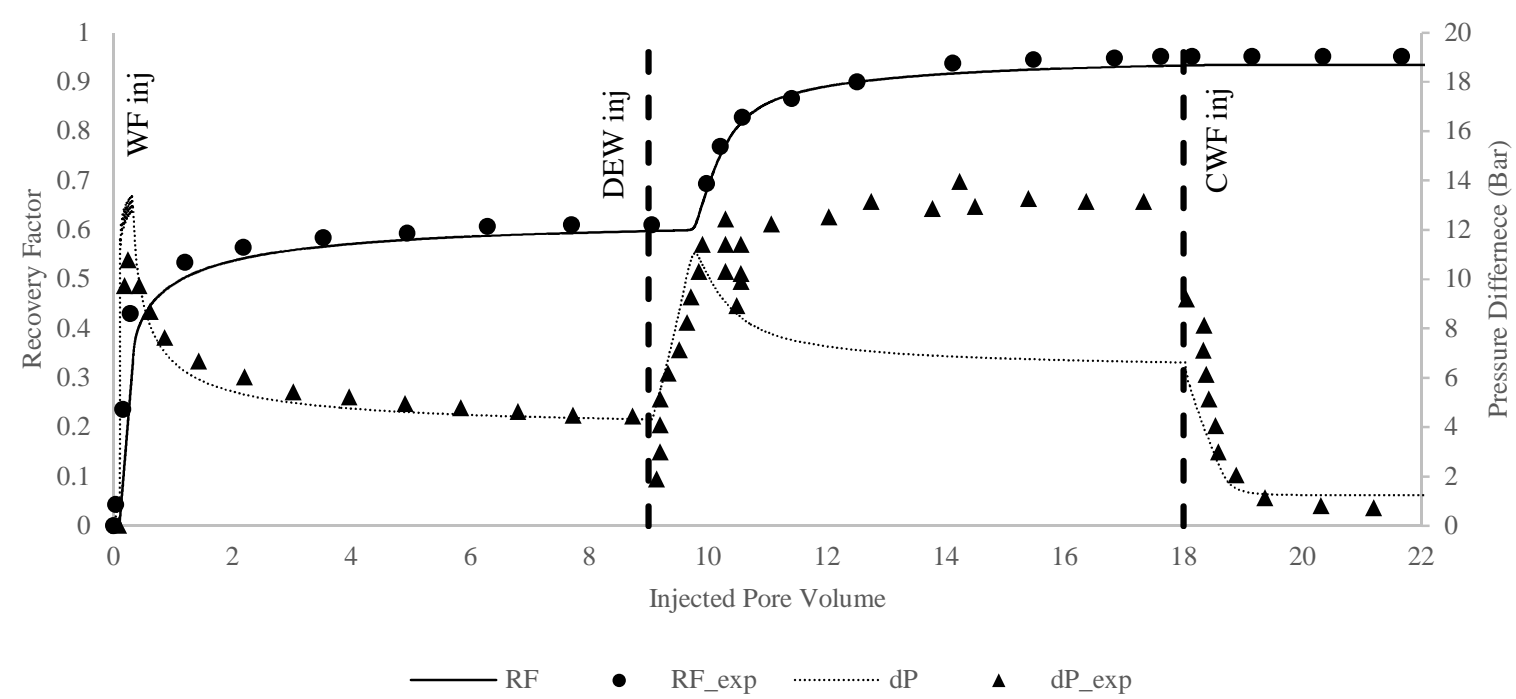

Figure 8. Continuous DEW injection: The recovery factor $(R F)$ is shown by the solid line. The pressure difference $(d P)$ is shown by the dashed line. The circular and triangular markers show the experimental data (Chernetsky et al., 2015). The vertical dashed lines indicate the beginning and the end of DEW. 


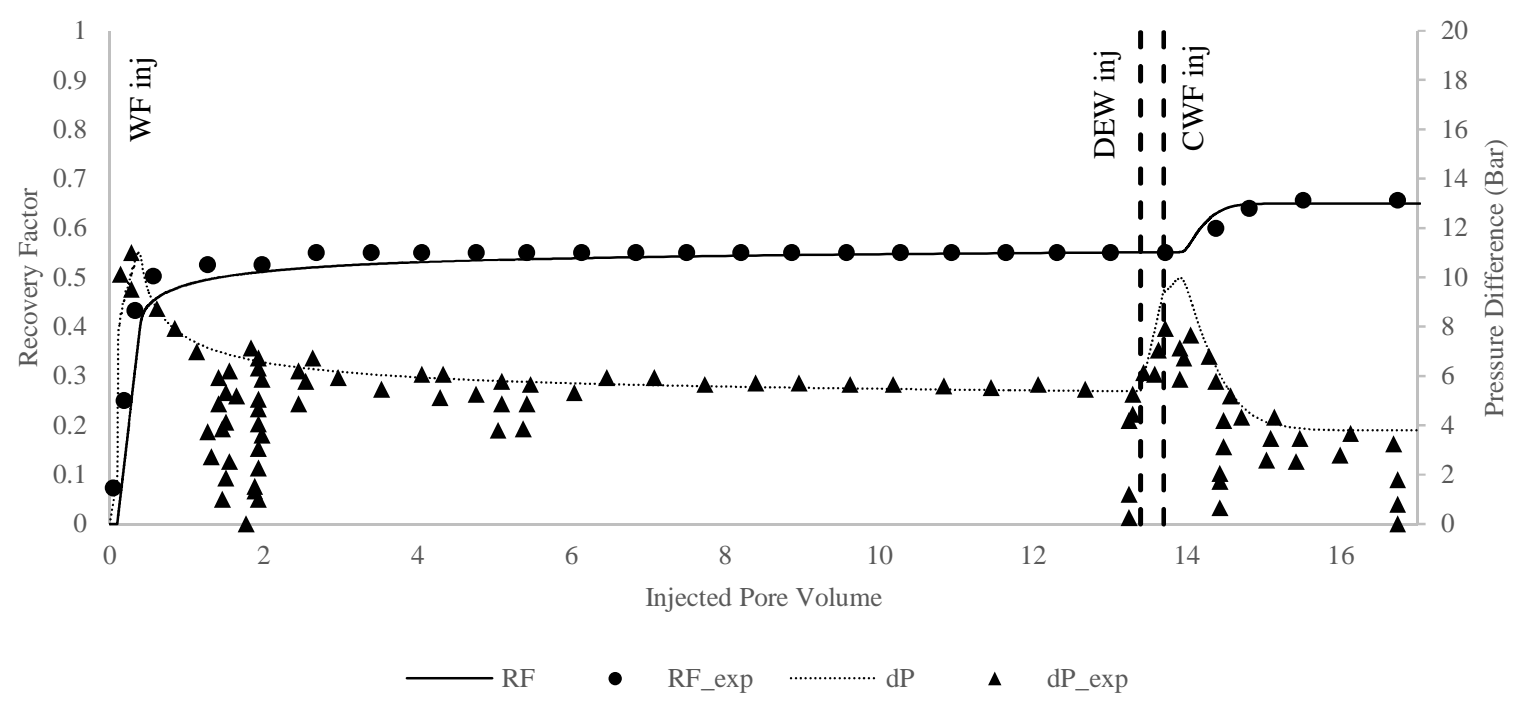

Figure 9. Slug DEW injection: The recovery factor $(R F)$ is shown by the solid line. The pressure difference (dP) is shown by the dashed line. The circular and triangular markers show the experimental data (Chernetsky et al., 2015). The vertical dashed lines indicate the beginning and the end of $D E W$.

\subsubsection{Sensitivity Analysis on Grid Size}

We study the effect of grid size on the 1D simulation results of injecting 9 pore volumes of water followed by 9 pore volumes of DME with a DME concentration of $10 w t \%$. The simulations are conducted for eight different grid sizes and the results are presented in Figure 10.
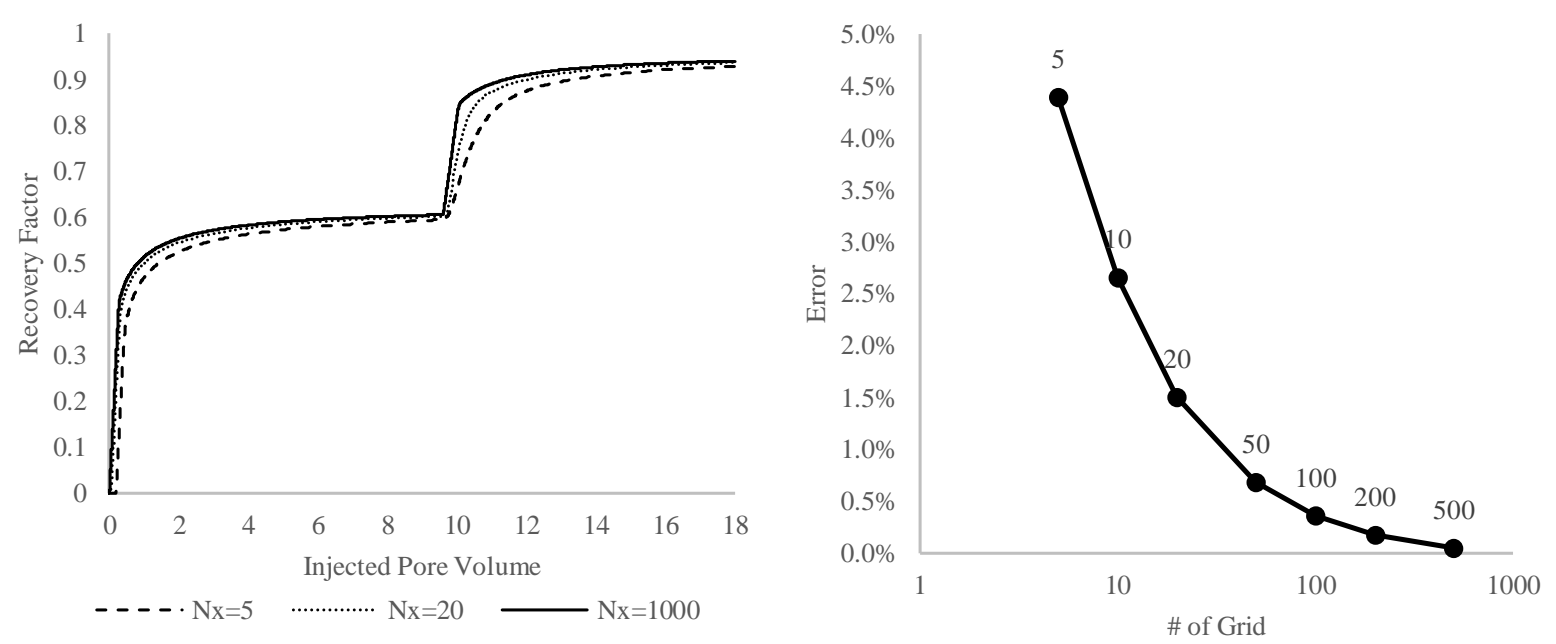

Figure 10. Mesh size effect on the numerical calculation of recovery (left) and its error (right) in $1 D$ core scale model.

Figure 10 (left) shows the grid sensitivity of the oil recovery for the coarse, medium and fine grid sizes. The ultimate oil recovery at the end of each stage (water flooding, DEW process) is almost equal for all grid sizes but the time between breakthrough and the ultimate recovery is smaller for the fine grid, due to the numerical diffusion.

Figure 10 (right) illustrates the numerical error of increasing the number of grid cells. The error is 
size (reference solution; $N x=1000$ ). The difference in the produced oil between coarse and fine grid size is less than $5 \%$ even for the very coarse grid $(N x=5)$. Additionally, the maximum difference between the calculated recovery factors for the coarse grid and reference grid is observed before the water breakthrough, and for the rest of the process the calculated error is almost negligible.

\subsubsection{Sensitivity Analysis on Slug Size}

The relation between the DME slug size and the recovery is investigated by conducting several simulations. The DME slug sizes were changed in each simulation and its impact on the ultimate recovery is presented in Figure 11. There is a sharp increase in the ultimate recovery when DME slug is increased from 0.2 to 1.8 pore volumes of the reservoir. As DME slug size increases above two pore volumes, only a small amount of extra oil can be recovered. Although Figure 11 gives an indication of the optimum slug size, i.e., the minimum amount of DME that yields a high recovery factor, estimating the optimal slug size requires an integrated economic evaluation. Later, we will show the optimum economic DME slug size for homogenous and heterogeneous reservoirs.

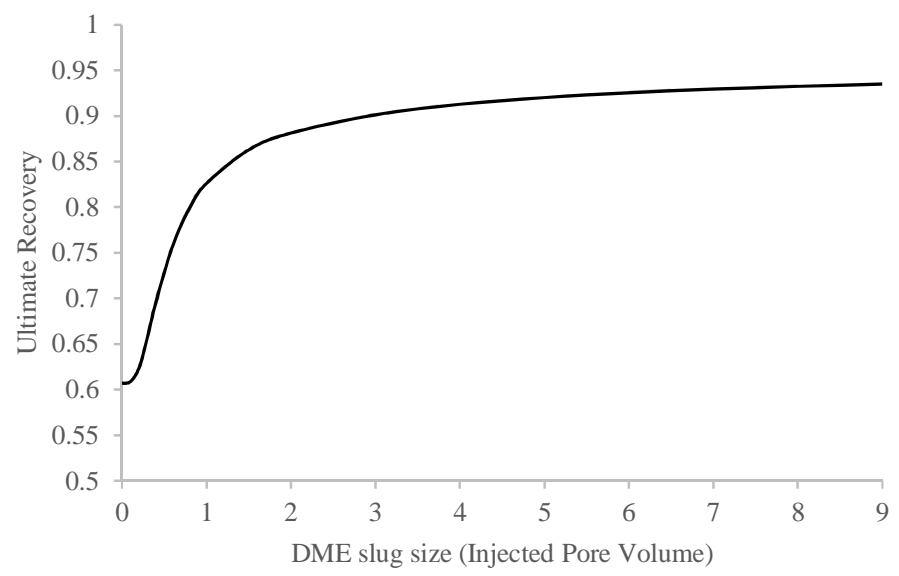

Figure 11. The effect of DME slug size on the ultimate recovery for the $1 D$ core scale model after 7 pore volumes $(P V)$ conventional waterflooding.

\subsection{Two-dimensional Homogeneous Chalk Reservoir Model}

Figure 12 shows the oil recovery factor of the chalk reservoir for two horizontal and vertical well completions. Since the reservoir is homogenous, the trend of recovery factor is identical for both schemes. The two vertical dashed lines indicate the start and the end of DEW injection. Initially, $70 \%$ of the oil reserve is produced by three pore volumes water flooding and more than $20 \%$ extra oil is produced by one pore volume DEW injection.

Figure 13 shows the cumulative amount of the injected and back-produced DME in the reservoir. Since the reservoir is homogeneous, almost all of the DME solvent is back-produced with chase water flooding. Due to the stable front in the homogenous reservoir, it takes one pore volume to back produce all the remaining DME by water injection. The amount of the produced DME is essential in the economic analysis.

Figure 14 compares the increased NPV of DME injection for both horizontal and vertical wells. The horizontal axis shows the DME slug size and the vertical axis shows the increased NPV of DME injection compared to a conventional water flooding. Note that the CAPEX of the vertical well is considered half 
the price of the horizontal well. The DEW injection has the largest profit for a homogenous reservoir when DME slug size is 0.4 pore volume for vertical wells and one pore volume for horizontal wells. In the homogenous model, the DME flows uniformly in the reservoir and no fingering takes place. Therefore, the back-produced DME is not available for reinjection in the same field.

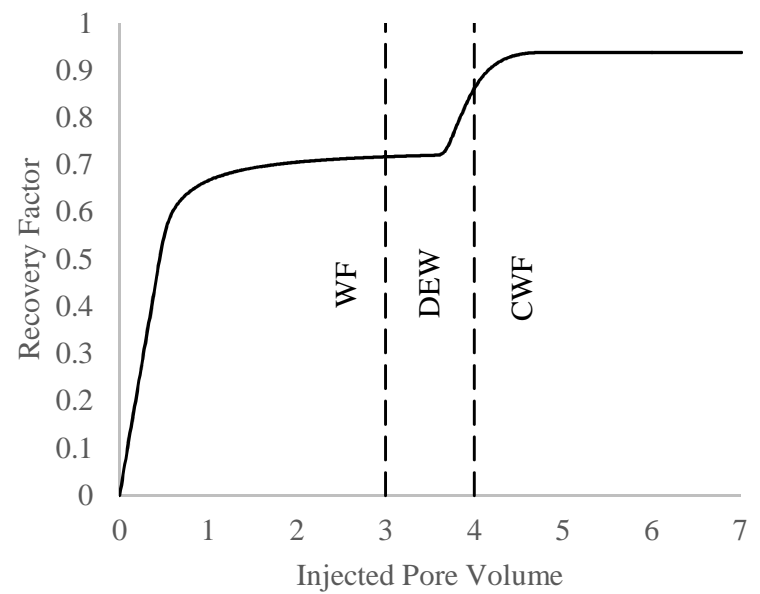

Figure 12. Recovery Factor of DEW flooding in the homogeneous $2 D$ model. The vertical dashed lines show the period of DME injection.

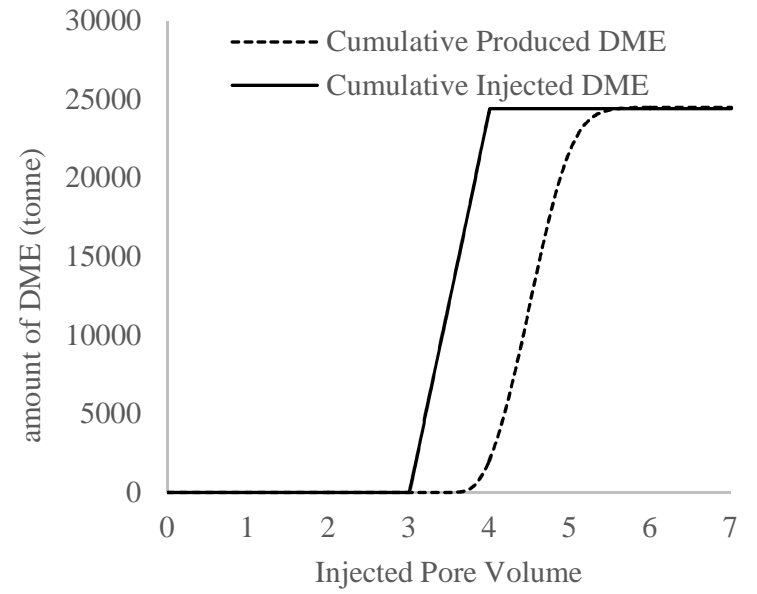

Figure 13. Cumulutive amount of injected and back produced DME for the homogeneous $2 D$ model.

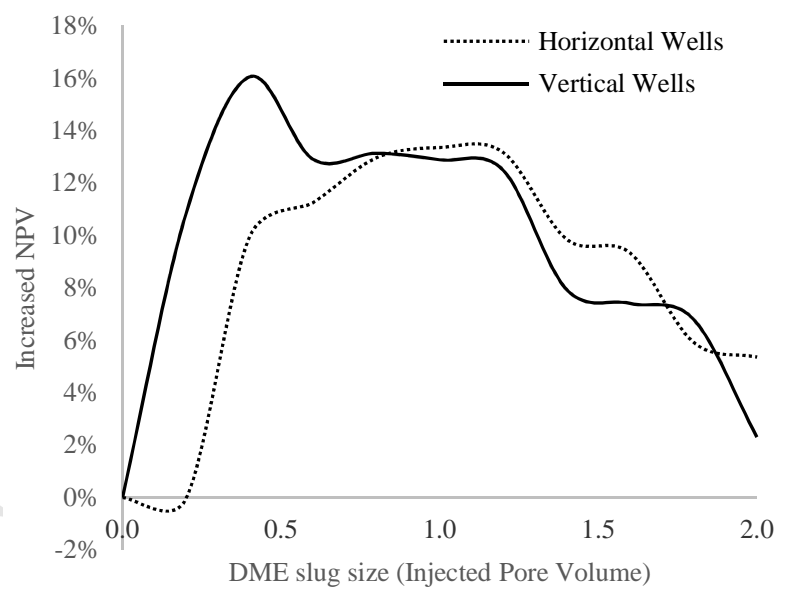

Figure 14. Effect of the DME slug size on the increased NPV compared to water flooding for a $2 D$ homogeneous chalk reservoir.

\subsection{Two-dimensional Heterogeneous Chalk Reservoir Scale Model}

Initially, the equivalent permeability values of each field (see the previous section on the permeability field generation) for two directions are calculated. A pressure difference is applied on the two sides of the field and the rate of water injection is calculated. Then, the equivalent permeability is determined by Darcy's law. 
Table 5 lists the equivalent permeability values for all of the six heterogeneous permeability fields for both $x$ and $y$ direction as well as the equivalent permeability between the two vertical wells. It shows that Field2 has the highest and Field6 has the lowest equivalent permeability. We could not find any correlations between the equivalent permeability and the NPV of DEW flooding.

Table 5. The equivalent permeability values of the heterogeneous fields for two different directions.

\begin{tabular}{|c|c|c|c|c|c|c|}
\hline Field & Field1 & Field2 & Field3 & Field4 & Field5 & Field6 \\
\hline$k_{e, x}(m D)$ & 0.320 & 0.610 & 0.449 & 0.608 & 0.417 & 0.187 \\
\hline$k_{e, y}(m D)$ & 0.242 & 0.249 & 0.272 & 0.387 & 0.217 & 0.012 \\
\hline$k_{e}$, vertical wells $(m D)$ & 0.295 & 0.385 & 0.355 & 0.502 & 0.305 & 0.035 \\
\hline
\end{tabular}

\subsubsection{Horizontal Wells}

The simulations are conducted with identical operating condition for all of the six heterogeneous permeability fields using horizontal wells at each side of the reservoir domain. The reservoir is flooded with three pore volumes of water, followed by one pore volume of DME injection and three pore volumes of chase water. Figure 15 illustrates the recovery factor of each heterogeneous chalk reservoir during DEW operation. It shows that the recovery factor is increased more than $15 \%$ in all of the heterogeneous chalk reservoirs by injecting one pore volume of DEW.

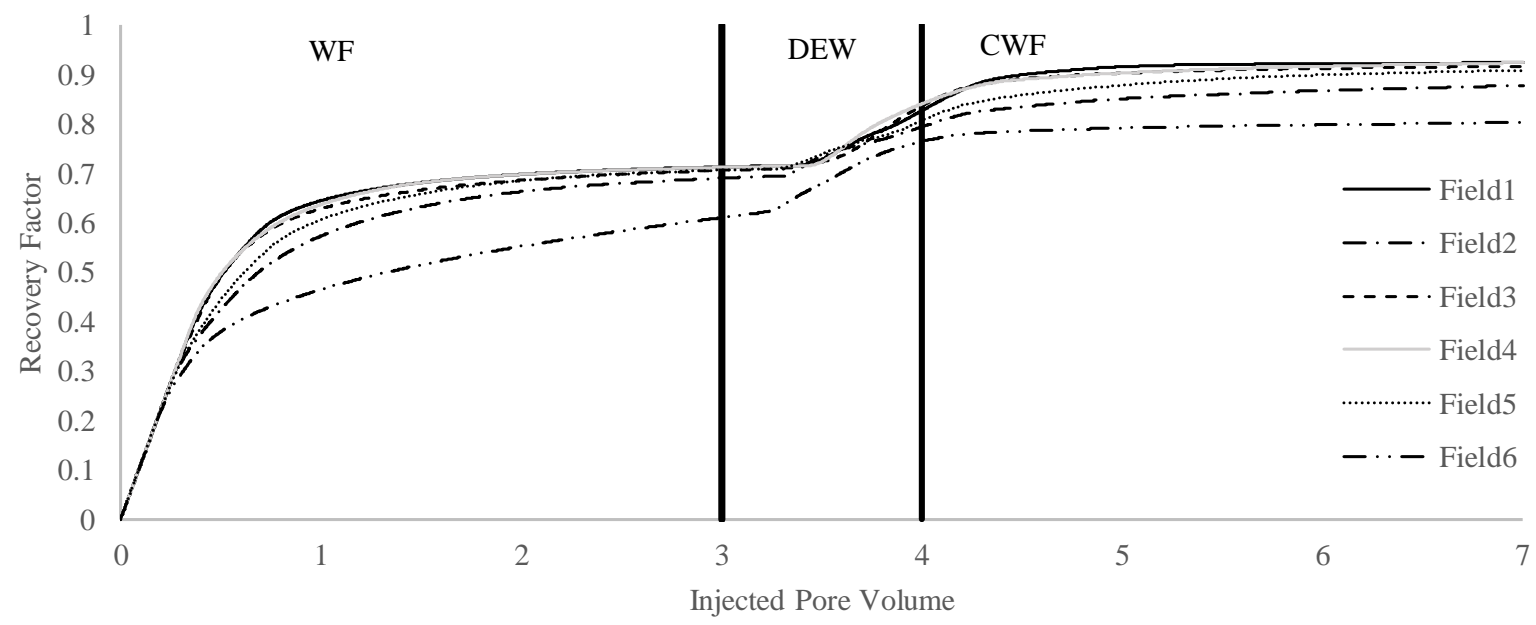

Figure 15. Increased recovery of DEW in heterogeneous chalk reservoirs for the horizontal well scheme.

The impact of heterogeneity on two-phase flow and DME transport is illustrated in Figure 16 for Field5 for the horizontal well scheme. Due to presence of several high permeable zones in Field5, we can observe channeling and an early breakthrough of DEW. 

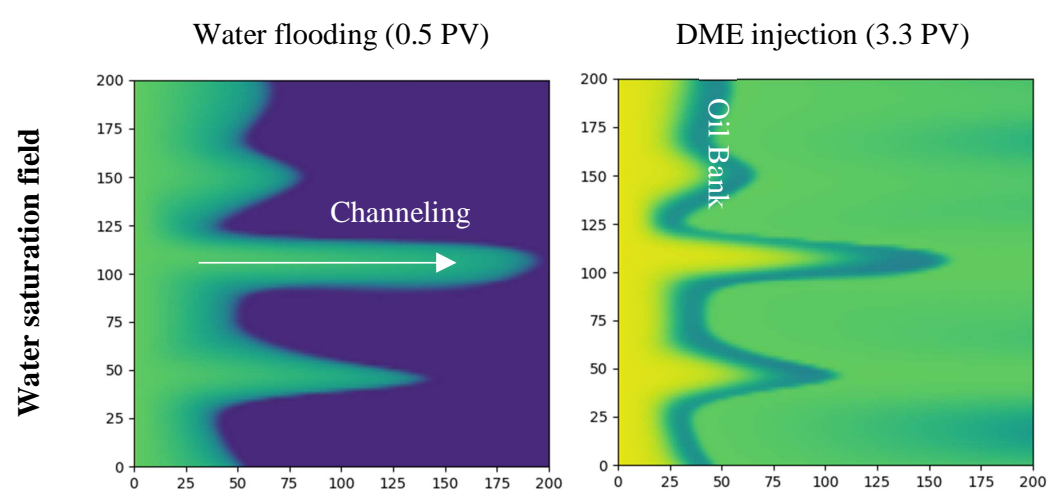

Chase water flooding (4.3 PV)
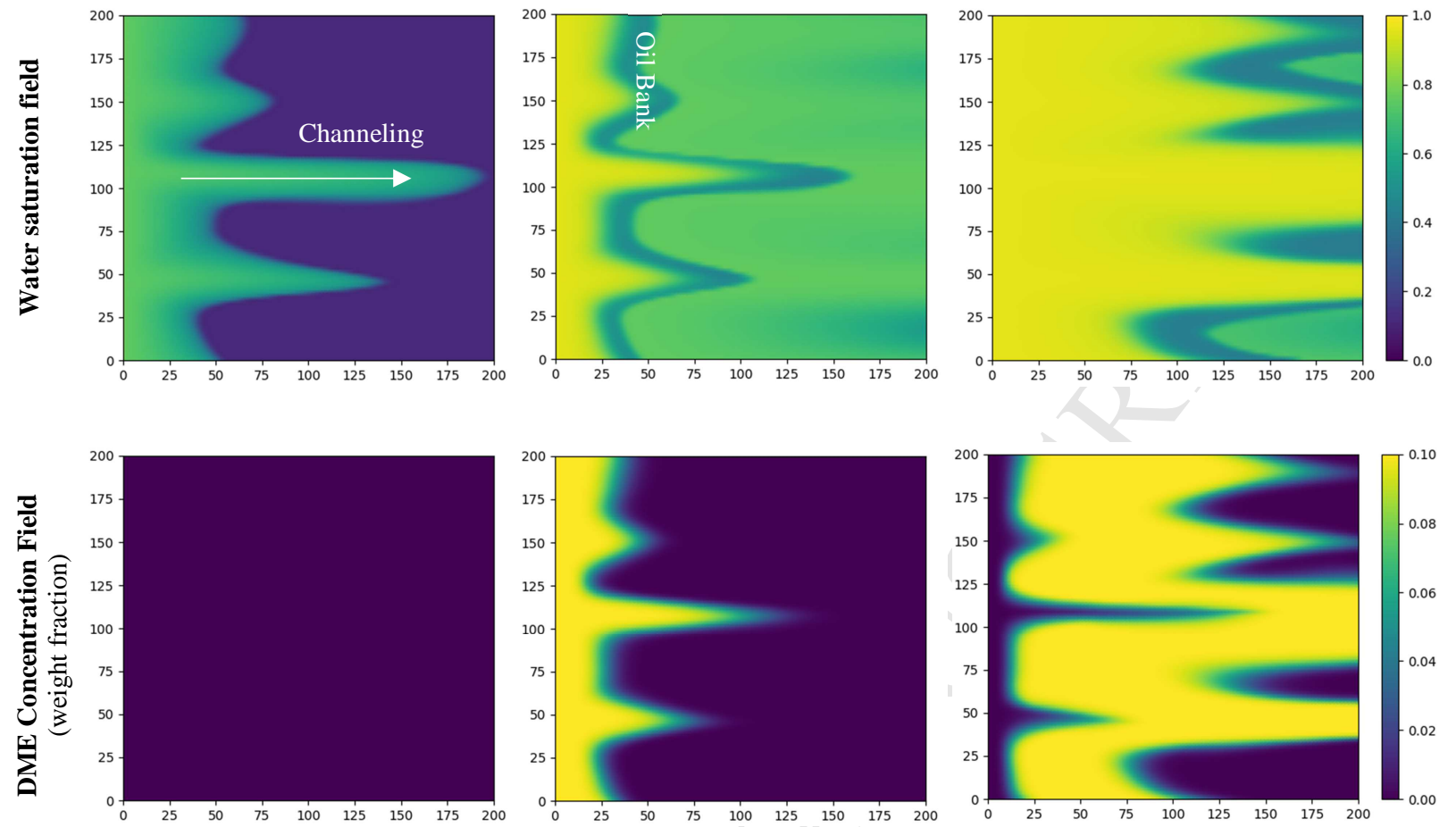

Figure 16. DME concentration and water saturation profile in the heterogeneous Filed5 for the horizontal well scheme. White arrow shows the direction of the fluid flow.

\section{NPV Analysis}

In this section, the NPV calculation for all of the heterogeneous reservoirs is presented. Figure 17 shows the increased NPV of DEW injection over conventional water flooding for six heterogeneous permeability fields. There are two bumps in the increased NPV for most of the cases. The first bump appears due to the sharp increase of the oil recovery when DME slug is increased from 0.0 to 0.4 pore volume. The second bump occurs due to the large recovery factor of DEW injection when DME slug is 1.2 pore volumes.

To understand the sensitivity of the results to the DME price, several simulations utilizing Field5 are conducted. We analyze the sensitivity of the NPV results for: 1) DME price of 0.1 to $0.6 \$ / \mathrm{kg}$ (Figure 18 , left) and 2) when the price of DME is linearly linked to the oil price (Figure 18, right).

Obviously, as DME price decreases, the profit of the project increases. The maximum DME price for a profitable DEW flooding is $0.6 \$ / \mathrm{kg}$ based on our calculations. The profit of the project has its maximum value when the oil price is between 70-80 $\$ / b b l$. Since DME price also increases with oil price, for the prices above $90 \$ / b b l$, the profit of the project decreases compared to 70-80 $\$ / b b l$ oil price. 

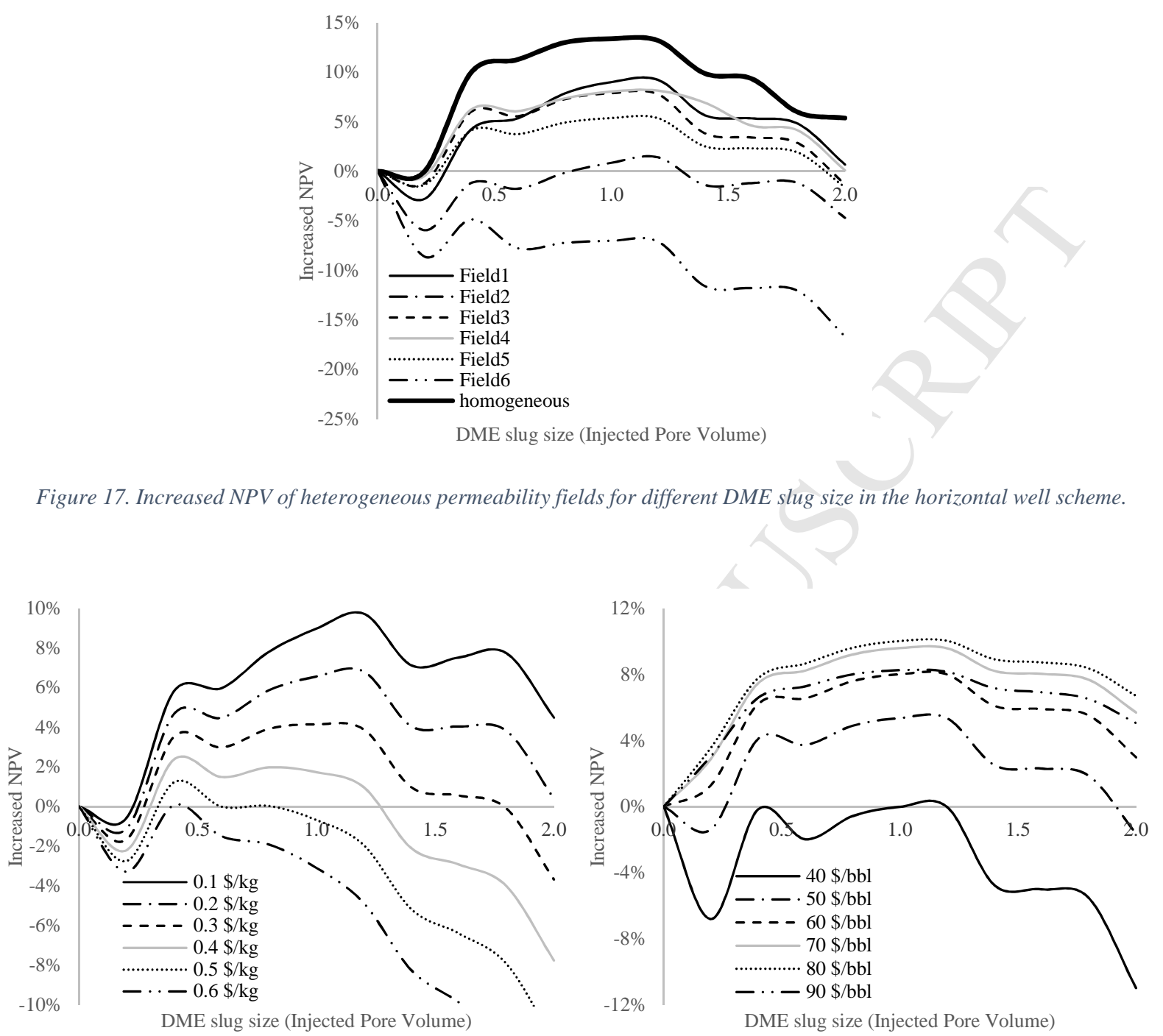

Figure 18. The effect of DME price (left) and oil price (right) on increased NPV for the heterogeneous Field5 with respect to the $D M E$ slug size in the horizontal well scheme.

To understand the heterogeneity effect on the increased NPV, the travel time of the fluid from the injector to the producer is analyzed. In Figure 19, the white marker line shows the time response (in pore volume) from the initial water flooding to the water breakthrough. The grey marker line shows the time response (in pore volume) from the start of DME injection until the first signs of the extra oil recovery is observed at the production well. The black marker line, shows the increased NPV for the scenario where 0.6 pore volume DME slug is injected. The results show that the early breakthrough in the reservoir has clearly a negative effect on the increased NPV for the studied heterogeneous permeability fields. This indicates that reservoirs with lower heterogeneity are the best candidates for the DEW flooding. 

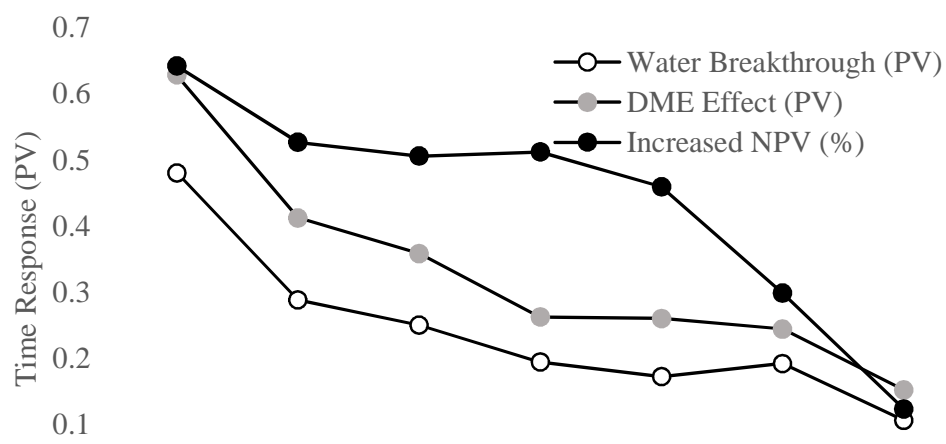

$$
0.1
$$

Hemo Field4 Field1 Field3 Field5 Field2 Field6

Figure 19. The time response (in pore volume) from the initial water flooding to the water breakthrough (white marker) and from the start of DME injection until the first signs of the extra oil recovery is observed at the production well (grey marker). The black marker shows the increased NPV for the scenario where 0.6 pore volume DME slug is injected for the horizontal scheme.

\subsubsection{Vertical Wells}

Figure 20 shows the recovery factor in DEW flooding for the vertical well injector and producer. The simulations are conducted with identical operating conditions for all of the six heterogeneous permeability fields. In general, the oil recovery in vertical scheme has lower values compared to the horizontal scheme (except for Field6) due to larger sweep efficiency. In the Field6, there is an extremely high permeable zone at one side of the reservoir, from which, the injected fluid channels to the horizontal producer, which leads to a low sweep. In the vertical scheme, due to the location of vertical wells with respect to the permeability field, the fluid may not transport only through the high permeable zone which makes it possible for DEW to sweep a larger area of the reservoir.

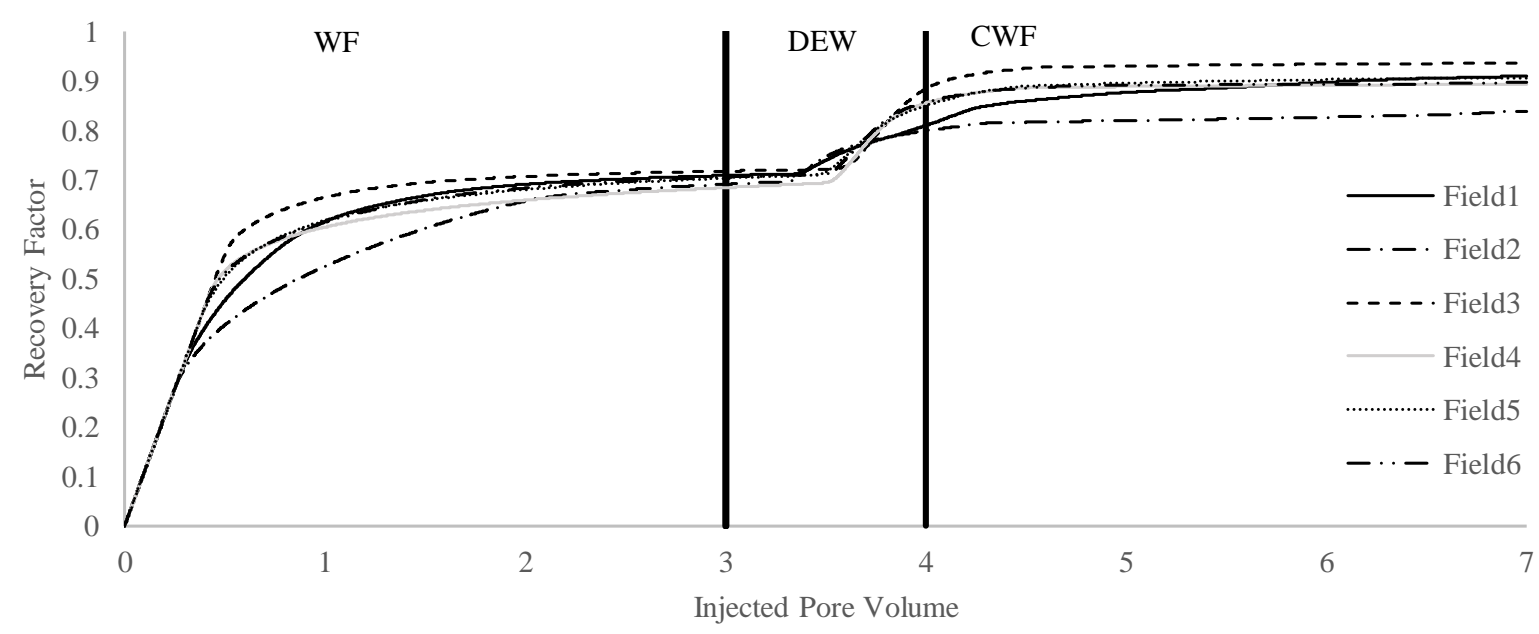

Figure 20. Increased recovery of DEW in heterogeneous chalk reservoirs for the vertical well scheme.

Figure 21 illustrates the water saturation and DME concentration profiles in Field5 for vertical well scheme. Same as horizontal well scheme, when DME molecules get in contact with the remaining oil, 
they partition into the oleic phase which results in oil swelling and visosity reduction, and mobilization of oil. In Figure 21 (top, middle), the darker area shows oil bank formation which is swept towards the production well.
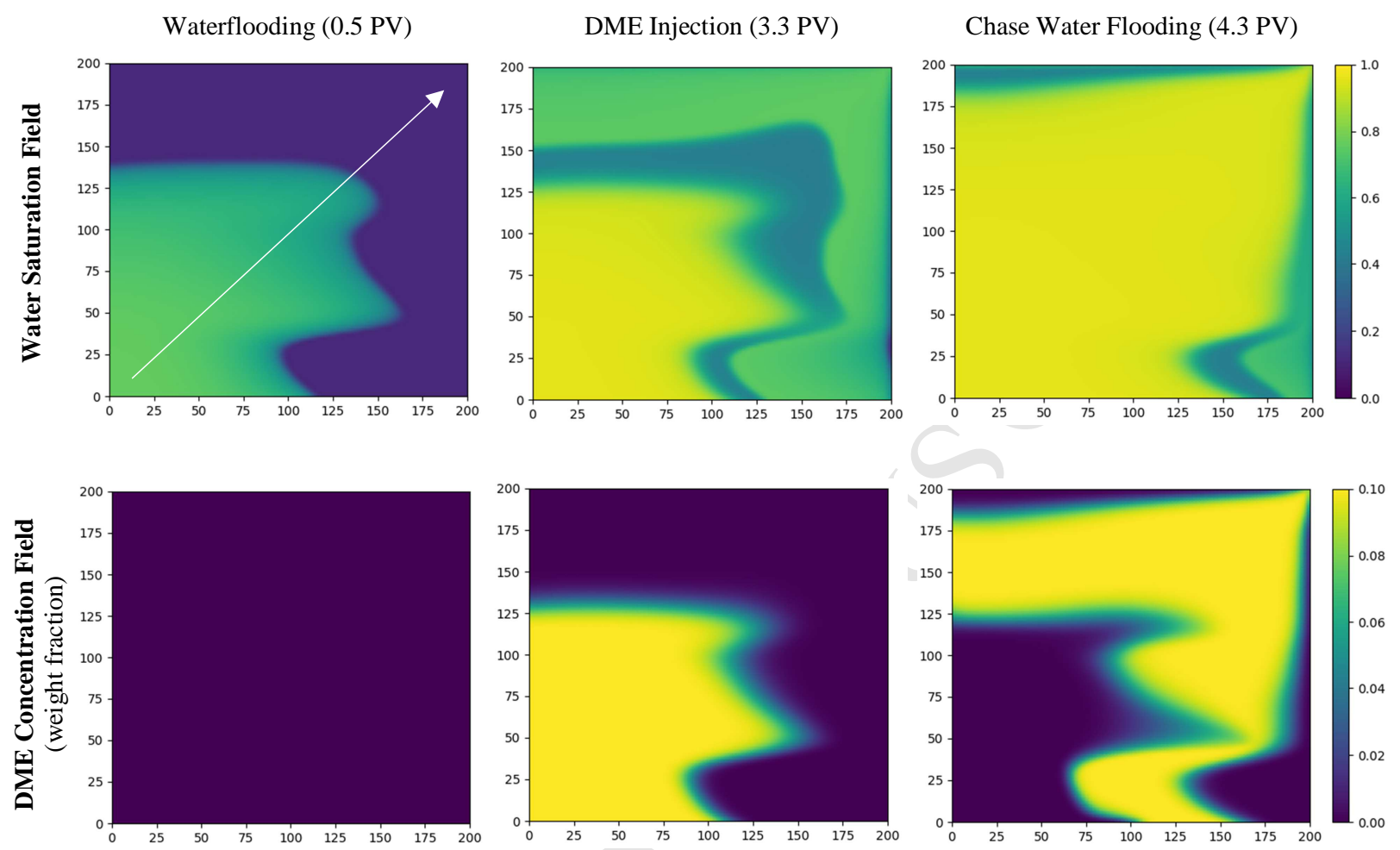

Figure 21. DME concentration and water saturation profile in the heterogeneous Filed5 for the vertical well scheme. White arrow shows the direction of the fluid flow.

\section{NPV Analysis}

Similar to the horizontal well scheme, the NPV calculations are conducted for all of the six heterogeneous permeability fields. As depicted in Figure 22, the homogeneous reservoir model gives better NPV results compared with the heterogeneous reservoirs. The increased NPV of vertical well scheme in Field3 and Field6 is larger than horizontal scheme while the rest of the heterogeneous fields have lower profit with vertical well completion. Additionally, we observed that the optimum DME slug size for solvent injection is 0.4 pore volume and there is no secondary bump in the increased NPV.

Similar to the horizontal well scheme, the sensitivity of the results to the DME price is studied by conducting several simulations utilizing Field5. Again, we analyze the sensitivity of the NPV results for: 1) DME price of 0.1 to $0.6 \$ / \mathrm{kg}$ (Figure 23, left), and 2) different oil prices with the price of DME linearly linked to the oil price (Figure 23, right). Figure 23 (left) shows that the optimum slug size for DME injection is hardly impacted by DME price compared to the horizontal well scheme; moreover, DEW flooding is feasible even for higher solvent prices. 

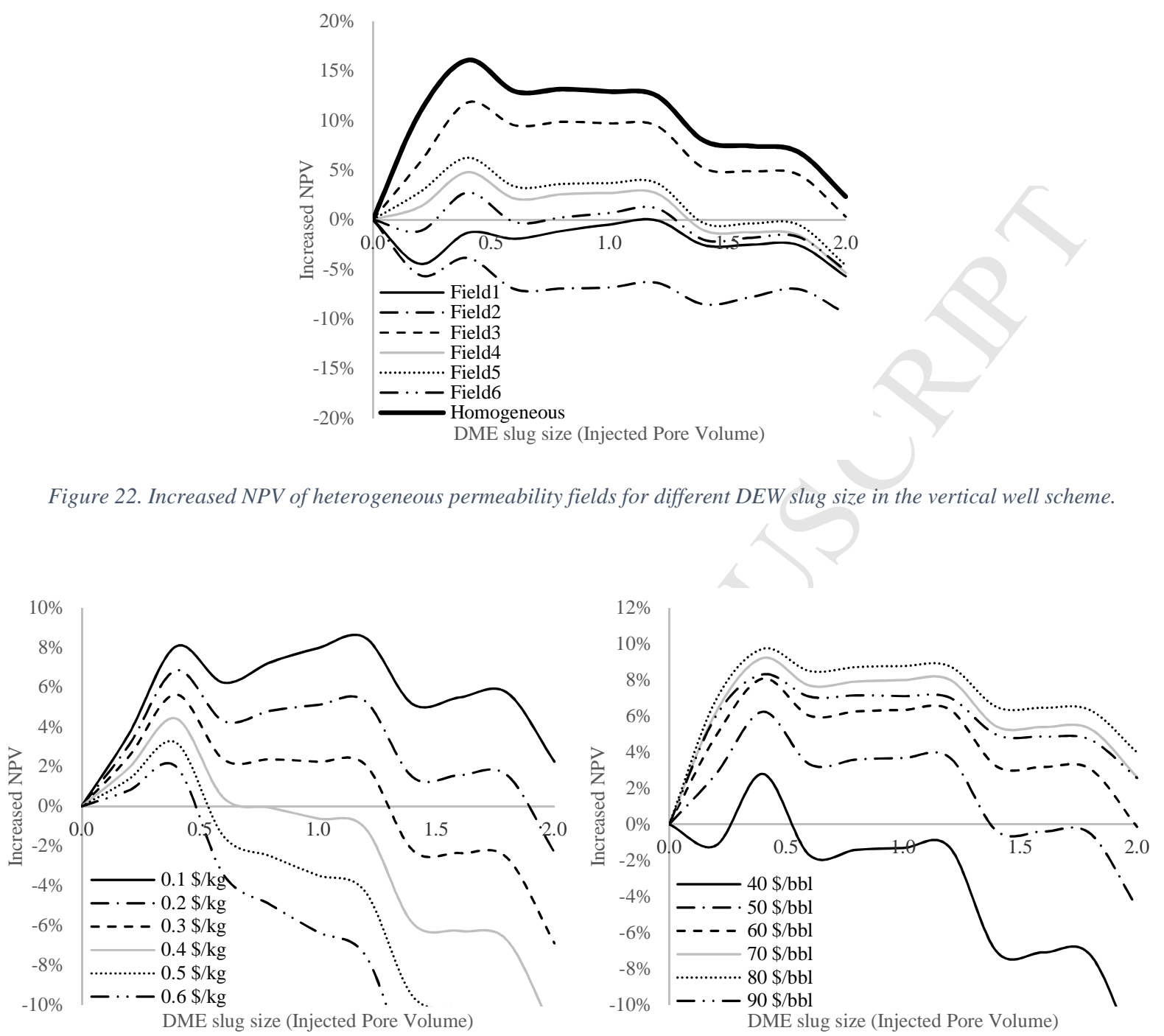

Figure 23. The effect of DME price (left) and oil price (right) on increased NPV for the heterogeneous Field5 with respect to the $D E W$ slug size in the vertical well scheme.

Figure 24 compares the water breakthrough, DME induced recovery, and increased NPV for six heterogeneous permeability fields when 0.6 PV DME is injected after 3 PV water flooding. The early breakthrough in the reservoir has negative effect on the increased NPV, which means that homogenous reservoirs are the ideal candidate for DEW flooding. 


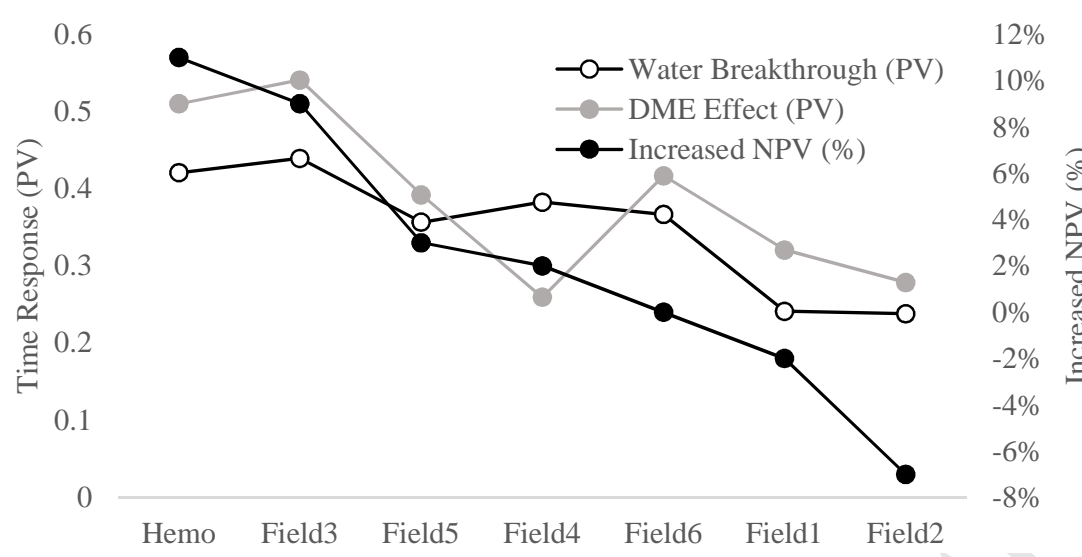
Figure 24. The time response (in pore volume) from the initial waterflooding to the water breakthrough (white marker) and from
the start of DME injection until the first signs of the extra oil recovery is observed at the production well (grey marker). The
black marker shows the increased NPV for the scenario where 0.6 pore volume DME slug is injected for vertical scheme.

\section{Conclusions}

In this study, a mathematical model is developed that considers all the suggested mechanisms for the DEW flooding. We extend the model by defining the residual oil saturation as a linear function of the DME concentration in the oil phase. We then utilize the history-matched model and conduct several simulations on six heterogeneous permeable reservoirs for vertical and horizontal well completions. Additionally, we calculate the increased Net Present Value of DEW flooding (compared to the conventional water flooding) with a DME concentration of $10 w t \%$ in each field. The key finding of this study are as follows:

- Our simulation results show that none of the previously reported mechanisms can explain the observed extra oil recovery, and more research is required to identify other mechanisms. The extended model can match the oil recovery and (to a lesser extent) the pressure drop experimental data.

- In DEW flooding, as DEW slug size increases, the ultimate recovery first increases sharply for the first two injected pore volumes. After that, the recovery only slightly increases by increasing the DEW slug size.

- In the studied heterogeneous chalk reservoirs, the optimum DME slug size for DEW flooding is 0.4 reservoir pore volume.

- The increased NPV of DEW compared to the conventional water flooding in horizontal well completion has larger values compared to the vertical well completion in most of the studied heterogeneous chalk fields.

- The NPV of DEW has large sensitivity to the DME price. For horizontal well scheme, the DEW flooding is profitable if the DME price is less than $0.6 \$ / \mathrm{kg}$.

- Heterogeneity has a negative impact on the increased NPV for the DEW flooding. 


\section{Reference}

Bezanson, J., Edelman, A., Karpinski, S., Shah, V.B., 2014. Julia: A fresh approach to numerical computing. arXiv preprint arXiv:1411.1607.

Buckley, J., Liu, Y., Monsterleet, S., others, 1998. Mechanisms of wetting alteration by crude oils. SPE journal 3, 54-61.

Buckley, J., Takamura, K., Morrow, N., others, 1989. Influence of electrical surface charges on the wetting properties of crude oils. SPE Reservoir Engineering 4, 332-340.

Buckley, J.S., 1994. Chemistry of the crude oil/brine interface, in: Proc. 3 Rd International Symposium on Evaluation of Reservoir Wettability and Its Effect on Oil Recovery. pp. 33-38.

Chahardowli, M., Farajzadeh, R., Bruining, H., 2016. Experimental investigation of the use of the dimethyl ether/polymer hybrid as a novel enhanced oil recovery method. Journal of Industrial and Engineering Chemistry 38, 50-60.

Chahardowli, M., Farajzadeh, R., Masalmeh, S.K., Mahani, H., Bruining, H., 2016. A Novel Enhanced Oil Recovery Technology Using Dimethyl Ether/Brine: Spontaneous Imbibition in Sandstone and Carbonate Rocks, in: SPE Annual Technical Conference and Exhibition. Society of Petroleum Engineers.

Chahardowli, M., Zholdybayeva, A., Farajzadeh, R., Bruining, H., 2013. Solvent-enhanced spontaneous imbibition in fractured reservoirs, in: EAGE Annual Conference \& Exhibition Incorporating SPE Europec. Society of Petroleum Engineers.

Chernetsky, A., Masalmeh, S., Eikmans, D., Boerrigter, P., Fadili, A., Parsons, C., Parker, A., Boersma, D., Cui, J., Dindoruk, B., others, 2015. A Novel Enhanced Oil Recovery Technique: Experimental Results and Modelling Workflow of the DME Enhanced Waterflood Technology, in: Abu Dhabi International Petroleum Exhibition and Conference. Society of Petroleum Engineers.

Christoffersen, K.R., Whitson, C.H., 1995. Gas/Oil Capillary Pressure of Chalk at Elevated Pressures. SPE Formation Evaluation 10, 153-159. https://doi.org/10.2118/26673-PA

Dagan, G., 2012. Flow and transport in porous formations. Springer Science \& Business Media.

Eftekhari, A.A., 2017. simulkade/JFVM.jl: JFVM.jl: A Finite Volume Tool for Solving Advection-Diffusion Equations. https://doi.org/10.5281/zenodo.847056

Eftekhari, A.A., Schüller, K., 2015. FVTool: a finite volume toolbox for Matlab. https://doi.org/10.5281/zenodo.32745

Foroozesh, J., Jamiolahmady, M., Sohrabi, M., 2016. Mathematical modeling of carbonated water injection for EOR and $\mathrm{CO} 2$ storage with a focus on mass transfer kinetics. Fuel 174, 325-332.

Fujimoto, K., Ohno, Y., Goto, S., Kajitani, S., Konno, M., Shikada, T., Suzuki, S., 2007. DME handbook, in: Tokyo: Japan DME Forum.

Groot, J., Chernetsky, A., Te Riele, P., Dindoruk, B., Cui, J., Wilson, L., Ratnakar, R., others, 2016a. Representation of Phase Behavior and PVT Workflow for DME Enhanced WaterFlooding, in: SPE EOR Conference at Oil and Gas West Asia. Society of Petroleum Engineers.

Groot, J., Eikmans, D., Fadili, A., Romate, J.E., 2016b. Field-Scale Modelling and Sensitivity Analysis of DME Enhanced Waterflooding, in: SPE EOR Conference at Oil and Gas West Asia. Society of Petroleum Engineers. 
Groot, J., Eikmans, D., Fadili, A., Romate, J.E., 2016c. Field-Scale Modelling and Sensitivity Analysis of DME Enhanced Waterflooding, in: SPE EOR Conference at Oil and Gas West Asia. Society of Petroleum Engineers.

Javanmard, H., Seyyedi, M., Nielsen, S.M., 2018. On Oil Recovery Mechanisms and Potential of DME-Brine Injection in the North Sea Chalk Oil Reservoirs. Industrial \& Engineering Chemistry Research.

Johnson, S.G., 2015. The NLopt nonlinear-optimization package.

Kechut, N.I., Jamiolahmady, M., Sohrabi, M., 2011. Numerical simulation of experimental carbonated water injection (CWI) for improved oil recovery and CO 2 storage. Journal of Petroleum Science and Engineering 77, 111-120.

Lake, L.W., Johns, R.T., Rossen, W.R., Pope, G.A., 2014. Fundamentals of enhanced oil recovery. Society of Petroleum Engineers.

Muggeridge, A., Cockin, A., Webb, K., Frampton, H., Collins, I., Moulds, T., Salino, P., 2014. Recovery rates, enhanced oil recovery and technological limits. Phil. Trans. R. Soc. A $372,20120320$.

Nick, H.M., Schotting, R., Gutierrez-Neri, M., Johannsen, K., 2009. Modeling transverse dispersion and variable density flow in porous media. Transport in porous media 78, 1135.

Parsons, C., Chernetsky, A., Eikmans, D., te Riele, P., Boersma, D., Sersic, I., Broos, R., 2017. Introducing a Novel Enhanced Oil Recovery Technology, in: IOR 2017-19th European Symposium on Improved Oil Recovery.

Pope, G.A., 1980. The application of fractional flow theory to enhanced oil recovery. Society of Petroleum Engineers Journal 20, 191-205.

Ratnakar, R.R., Dindoruk, B., Wilson, L., 2016. Experimental investigation of DME-watercrude oil phase behavior and PVT modeling for the application of DME-enhanced waterflooding. Fuel 182, 188-197.

Ratnakar, R.R., Dindoruk, B., Wilson, L., 2016. Use of DME as an EOR Agent: Experimental and Modeling Study to Capture Interactions of DME, Brine and Crudes at Reservoir Conditions, in: SPE Annual Technical Conference and Exhibition. Society of Petroleum Engineers.

Ratnakar, R.R., Dindoruk, B., Wilson, L.C., 2017a. Development of empirical correlation for DME-partitioning between brine and crudes for enhanced waterflooding applications. Journal of Petroleum Science and Engineering.

Ratnakar, R.R., Dindoruk, B., Wilson, L.C., 2017b. Phase behavior experiments and PVT modeling of DME-brine-crude oil mixtures based on Huron-Vidal mixing rules for EOR applications. Fluid Phase Equilibria 434, 49-62.

Riazi, M., Sohrabi, M., Jamiolahmady, M., Ireland, S., 2009. Oil recovery improvement using CO2-enriched water injection, in: EUROPEC/EAGE Conference and Exhibition. Society of Petroleum Engineers.

Riele, P. te, Parsons, C., Boerrigter, P., Plantenberg, J., Suijkerbuijk, B., Burggraaf, J., Chernetsky, A., Boersma, D., Broos, R., 2016. Implementing a Water Soluble Solvent Based Enhanced Oil Recovery Technology-Aspects of Field Development Planning, in: SPE EOR Conference at Oil and Gas West Asia. Society of Petroleum Engineers.

Robin, M.J.L., Gutjahr, A.L., Sudicky, E.A., Wilson, J.L., 1993. Cross-correlated random field generation with the direct Fourier transform method. Water Resources Research 29, 2385-2397. 
521

522

523

524

525

526

Tweheyo, M.T., Talukdar, M.S., Tors ${ }^{2}$ eter, O., 2001. Hysteresis effects in capillary pressure, relative permeability and resistivity index of north sea chalk, in: Paper SCA 2001-65 Presented at the International Symposium of the Society of Core Analysts Held in Edinburgh, UK. 
- Oil swelling, and viscosity reduction are not the only mechanism in DEW

- A new mathematical model is suggested for DEW flooding

- Horizontal well completion has better NPV

- Heterogeneity has negative effect on NPV results of DEW 


\begin{tabular}{|llll|}
\hline Nomenclature & $p$ & Pressure of the phase $i$ [Pa] \\
EOR & Enhanced oil recovery & $p_{c}$ & Capillary pressure [Pa] \\
DME & Dimethyl ether & $p_{c e}$ & Capillary entry pressure [Pa] \\
DEW & DME enhanced water-flooding & $\lambda^{\prime}$ & Sorting factor [-] \\
CWF & Chase water flooding & $S_{o r}$ & Residual oil saturation [-] \\
NPV & Net Present Value & $S_{o r, W F}$ & Residual oil saturation that is measured for the \\
PV & Pore volume & & conventional water flooding without DME [-] \\
CAPEX & Capital expenditures & $c_{o, D E W}$ & Equilibrium concentration of DME in the oil \\
OPEX & Operating expenses & & phase for the DEW flooding [-] \\
& & $S_{o r, D E W}$ & Residual oil saturation to DEW flooding [-] \\
$S$ & Saturation [-] & $R_{t}$ & Cash flow [DKK] \\
$\rho$ & Fluid density [kg/m $\left.{ }^{3}\right]$ & $N$ & Total number of periods [-] \\
$\mathbf{u}$ & Darcy velocity [m/s] & $\lambda$ & Correlation length [m] \\
$\varphi$ & Porosity [-] & $h$ & Euclidean distance [m] \\
$c$ & Mass fraction of DME in the phase $i[-]$ & $\mu$ & Mean permeability [m $\left.{ }^{2}\right]$ \\
$K$ & Partition coefficient [-] & $\sigma_{f}^{2}$ & Permeability variance [m $\left.{ }^{2}\right]$ \\
$k$ & Permeability [m $\left.{ }^{2}\right]$ & subscripts & \\
$k_{r}$ & Relative permeability of the phases $[-]$ & $w$ & water phase \\
$\mu_{i}$ & Fluid viscosity of the phase $i$ [Pa.s] & $o$ & oil phase \\
\hline
\end{tabular}

